\section{Co-creating services-conceptual clarification, forms and outcomes}

Co-creating services

Anna-Sophie Oertzen

Department of Marketing and Supply Chain Management, School of Business and Economics, Maastricht University, Maastricht, The Netherlands and

Köln International School of Design, Technical University of Applied Sciences Cologne, Cologne, Germany

Gaby Odekerken-Schröder

Department of Marketing and Supply Chain Management, School of Business and Economics, Maastricht University, Maastricht, The Netherlands

Saara A. Brax

School of Business and Management, Lappeenranta University of Technology, Lappeenranta, Finland, and

Birgit Mager

Köln International School of Design, Technical University of Applied Sciences Cologne, Cologne, Germany
641

Received 12 March 2017 Revised 24 September 2017 7 April 2018 Accepted 24 May 2018

\begin{abstract}
Purpose - The purpose of this paper is to assess, clarify and consolidate the terminology around the cocreation of services, establish its forms and identify its outcomes, to resolve the conceptual pluralism in service co-creation literature.

Design/methodology/approach - A focused literature review screened the articles published in five major service research journals to determine relevant contributions on the concept of co-creation of services. Then, a thematic analysis identifies the forms, themes and outcomes of co-creating services in the set of 80 qualifying articles. Findings - The study reduces conceptual pluralism by establishing different forms of co-creating services and developing an explicit definition of co-creation in services. The authors develop an integrative framework that recognizes involvement, engagement and participation as prerequisites for co-creation. Relating to the different phases of the service process, the specific co-creation forms of co-ideation, co-valuation, co-design, co-testing and co-launching are classified as regenerative co-creation, while the specific co-creation forms of co-production and co-consumption are recognized as operative co-creation. Both beneficial and counterproductive outcomes of co-creation are identified and arranged into a typology.

Research limitations/implications - The integrative framework illustrates that service providers and customers are involved, engaged and participate in co-creating services, which manifests in specific forms of co-creation; they attain beneficial and counterproductive outcomes (personal, social, hedonic, cognitive, economic and pragmatic); and are influenced by a contextual multi-actor network.

Practical implications - Co-creation in services is actionable; the typology of outcomes suggests service managers ways to motivate customers and employees to participate in co-creating services.

Originality/value - This paper defines and establishes the conceptual forms of co-creating services and the identified outcomes, and develops an integrative framework of co-creation in services.

Keywords Service co-creation, Engagement, Participation, Co-production, Co-design, Involvement Paper type Research paper

(c) Anna-Sophie Oertzen, Gaby Odekerken-Schröder, Saara A. Brax and Birgit Mager. Published by Emerald Publishing Limited. This article is published under the Creative Commons Attribution (CC BY 4.0) licence. Anyone may reproduce, distribute, translate and create derivative works of this article (for both commercial \& non-commercial purposes), subject to full attribution to the original publication and authors. The full terms of this licence may be seen at http://creativecommons.org/licences/by/4.0/legalcode

Funding: this project has received funding from the European Union's Horizon 2020 Research and Innovation Programme under the Marie Sklodowska-Curie Grant Agreement No. 642116.
\end{abstract}

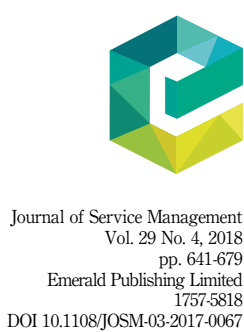


JOSM

29,4

642

\section{Introduction}

Organizations are increasingly adopting strategies to co-create with their customers: to improve the service experience, DHL hosts co-design workshops with customers; LEGO develops new offerings with lead users; and Netflix launched a competition to improve its services with its online community (Chesbrough, 2011; DHL Solutions \& Innovations, 2017; Prpić et al., 2015). Co-creation is rooted in the verb create, which is defined as bringing something into existence, causing something to happen as a result of one's actions, and in $c o$-, which means together with another or others (Oxford Dictionaries, 2018). In service management, co-creation refers to the service process and the service product; service providers aim to co-create with customers and other actors to create distinctive services, reduce costs or improve service performance. Co-creation has become a central theme in service management literature because customers and other actors function as active participants in services (Galvagno and Dalli, 2014; Grönroos and Voima, 2013; Vargo and Lusch, 2016).

This study sets out to organize the conceptual pluralism hindering the development of the research topic. Despite the increasing attention on the concept of co-creation in services, the published reviews (e.g. Galvagno and Dalli, 2014; Ranjan and Read, 2016; Voorberg et al., 2015) and the conceptual works (e.g. Grönroos and Voima, 2013; Payne et al., 2008; Prahalad and Ramaswamy, 2004a, b), the extant literature has not been consolidated into a shared definition and a comprehensive analysis of the phenomenon. This causes different delineations to proliferate, increasing confusion around "co-creation" (Dong and Sivakumar, 2017; Saarijärvi et al., 2013; Voorberg et al., 2015).

The purpose of the current paper is to synthesize and develop knowledge about the co-creation of services, that is, the activity, practice or process of jointly creating services in specific business contexts. Here, co-creation of services is not examined as the abstract and universal principle of value creation often manifested in the literature inspired by the service-dominant (S-D) logic approach (cf. Vargo and Lusch, 2004), but as an optional collaborative act in the customer-provider interface (a detailed discussion follows in Section 1.1). This paper, in turn, makes a clear distinction between the co-creation of value and the co-creation of services. The value co-creation view presumes that the provider joins the customer's value creation activities as a co-creator of value during the consumption process (Grönroos and Voima, 2013). The co-creation of services view does not specify whether the provider joins the customer's sphere or vice versa; instead, it concentrates on the mutual creation of services during service processes and service innovation activities.

To transform the relatively abstract discussions on co-creating services to applicable frameworks serving further theoretical and practical analyses, the present research considers three main questions:

RQ1. How does the concept of "co-creation of services" relate to other terms that address the collaboration of the service provider and the customer(s) in a service process or a service event?

$R Q 2$. How can the co-creation of services be defined?

$R Q 3$. What outcomes may follow from co-creating services?

In line with MacInnis' (2011) notion of different types of conceptual advancement, the present study offers four contributions to service management literature: first, it reduces conceptual pluralism around co-creating services by delineating its relationship to related terminology, such as involvement, engagement, participation, co-design, co-production and co-consumption; second, it identifies an explicit definition of the co-creation of services; third, it provides a differentiated terminology on the outcomes from co-creating services; and finally, it develops an integrative framework that offers a holistic explanation of the co-creation of services. 
In response to the research questions, the current focused literature review builds on extant conceptualizations of co-creation and related terminology in service literature. This focused review imitates the systematic review method (SLR) but is not framed as exhaustively; to effectively direct the focus of the analysis on co-creation of services and to ensure the analysis focuses on high-quality scholarly contributions, the study targets the five Social Science Citation Index (SSCI) rated "generic," i.e., not industry specific, service research journals: Journal of Service Management, Journal of Services Marketing, Journal of Service Research, Journal of Service Theory and Practice and Service Industries Journal.

This paper begins with an overview of the services research literature that examines the collaborative act in the customer-provider interface, outlining its evolution and pointing tensions. This is followed by the methodology section, which explains the focused literature review approach. Moving to the findings, first the terminology parallel to or corresponding with co-creation of services is examined and reflected against the broader literature base. Second, the results of the thematic analysis of qualifying articles that discovers 63 conceptualizations of co-creation and related terminology are reported and an explicit definition of co-creating services is developed. Third, the review results extend Verleye's (2015) work on the dimensions of the co-creation experience by arranging both beneficial and counterproductive outcomes in the literature into a typology of outcomes in co-creating services in a business context. Finally, the findings of the focused literature review are combined into an integrative conceptual framework. The paper concludes by discussing promising opportunities for service research, managerial takeaways and limitations.

\subsection{Evolution and tensions of the service co-creation literature}

The participation or involvement of customers in the processes of service providers has been a much-discussed topic for decades. Fuchs (1968) was the first to specifically propose the consumer as a factor in production in his seminal work on the service economy. In the 1970s, Levitt (1976) and Lovelock and Young (1979) suggested industrializing personal service to improve productivity for providers. In the 1980s, to increase productivity and customer satisfaction, Mills and Morris (1986) recommended considering customers as temporary, partial employees. In the 1990s, Dabholkar (1990) and Cermak et al. (1994) claimed that the inclusion of customers in the service production and delivery phases enhances service quality perceptions, repurchases and referrals.

The current analysis recognizes that with the start of the 2000s, the mindset around customer-provider collaboration shifted. Instead of viewing customers as productivity inputs and resources to rationalize production processes (here labeled as the first generation perspective), they were more broadly recognized as active collaborators in the business system and co-creation efforts became emphasized as the next frontier of competitive strategy (second generation) (Bendapudi and Leone, 2003; Prahalad and Ramaswamy, 2000, 2004a; Zwick et al., 2008). Table I provides a detailed comparison of the two generations of theorizing around the collaborative act in the customer-provider interface.

While the first generation view considers the customer as a temporary participant and a resource in the actual service process (Kelley et al., 1990; Mills and Morris, 1986), the second generation promotes involving the customer in the service system more broadly and in various stages and functions of the service value chain. This involvement of customers can extend throughout the entire innovation process for a service, from idea generation to the end use (Mele et al., 2014). Correspondingly, the communication between the provider and customer has evolved from sporadic, unidirectional and less transparent to frequent, bidirectional and transparent dialogue (Chathoth et al., 2013; Gustafsson et al., 2012; Prahalad and Ramaswamy, 2004a). Both parties must perceive their relationship as beneficial in order to continue (De Wulf et al., 2001), which highlights the customer as part of the social relations of production (Zwick et al., 2008). 
JOSM

29,4

\section{4}

(2) Collaboration duration

(3) Collaboration communication

(4) Collaboration relationship

(5) Collaboration focus

(6) Collaboration stage

(7) Collaborating actors

(8) Collaboration initiation

(9) Desired outcomes

Table I.

Two generations of provider-customer collaboration 1st generation on customer-provider collaboration

Customer involvement, customer participation, co-production, customers as (partial) employees, joint production

Temporary (Kelley et al., 1990; Mills and Morris, 1986)

Sporadic, unidirectional and less transparent (Kelley et al., 1990; Mills and Morris, 1986; Prahalad and Ramaswamy, 2004a)

The partial employee (Mills and Morris, 1986), putting customers to work to rationalize production processes (Zwick et al., 2008)

Provider centric (Cermak et al., 1994; Lovelock and Young, 1979)

In the service production and service delivery stages (Dabholkar, 1990; Lovelock and Young, 1979)

Provider-customer (e.g. Kelley et al., 1990; Mills and Morris, 1986)

The provider enables the involvement and invites the customer to participate (Normann and Ramirez, 1993; Ramirez, 1999)

Desired outcomes for the provider are of economical nature and include productivity and process gains, such as savings in time, money and effort (Dabholkar, 1990; Lovelock and Young, 1979) 2nd generation on customer-provider collaboration

Customer involvement, customer participation, co-creation, co-innovation, co-ideation, co-valuation, co-design, co-test, co-launch, co-investment, co-production, co-consumption

Temporary or continuous (Mele et al., 2014)

Frequent, bidirectional and transparent dialogue (Chathoth et al., 2013; Gustafsson et al., 2012; Prahalad and Ramaswamy, 2004a)

"Reconfiguring social relations of production" that foster contingency, playfulness and experimentation

(Zwick et al., 2008, p. 184)

Customer centric and experience centric (Chathoth et al., 2013; Prahalad, 2004) From co-ideation to co-consumption (Quero and Ventura, 2015; Russo-Spena and Mele, 2012)

Multi-actor network (Pirinen, 2016; Quero and Ventura, 2015)

Involvement may be initiated by the provider inviting actors to participate (Kazadi et al., 2016), the provider offering a platform for co-creation (Ogawa and Piller, 2006), the customer initiating the co-creation (Oliveira and von Hippel, 2011) or cocreation happening outside of the provider's focus, such as in online communities and the commons (Zwass, 2010)

Diverse set of desired outcomes for the provider and the customer, such as wellbeing (Engström and Elg, 2015), relationship quality (So et al., 2016), innovation (Ordanini and Parasuraman, 2011) and launch support (Rusanen et al., 2014)

These generations of thought are reflected in the normative and managerially targeted content in this body of knowledge. During the first generation of customer-provider collaboration, the collaboration was steered by a provider-centric mindset (Dabholkar, 1990; Lovelock and Young, 1979). This changed with the second generation; the collaboration focus is now rather oriented toward the customer and experiences (Chathoth et al., 2013; Prahalad, 2004). With a change in focus came also a transformation in collaboration initiation. Before, the provider enabled and invited the customer to participate (Normann and Ramirez, 1993; Ramirez, 1999). This changed to a more variable constellation, in which the provider or the customer may initiate collaboration (Kazadi et al., 2016; Oliveira and von Hippel, 2011), the provider may only offer the platform for collaboration (Ogawa and Piller, 2006), or the customer may engage in collaboration outside of the provider focus (Zwass, 2010).

Another important facet of the evolvement is that the customer-provider collaboration developed from a focus on the dyad to a more encompassing picture that considers the influence of a multi-actor context (Mills and Morris, 1986; Pirinen, 2016). The service context 
is described as a multifaceted and dynamic social and economic system that is composed of an actor network and guiding institutions (Akaka and Vargo, 2015).

Finally, the desired outcomes following the process of co-creating services have changed from mainly economical nature (Dabholkar, 1990; Lovelock and Young, 1979) to being much more multidimensional. For the second generation of customer-provider collaboration, desired outcomes are considered for both the provider and the customer, and they anticipate well-being, relationship quality and innovation, among others (Engström and Elg, 2015; So et al., 2016, Ordanini and Parasuraman, 2011).

Changes in the style of debate can also be associated with the generations of thought. During the first generation, the tension is framed between the establishing service field toward the traditional disciplines that, allegedly, considered goods and service contexts as no different. After entering the second generation view of co-creation, tensions were reframed within the stream of service research. In particular, current literature features an ongoing debate about the true meaning of co-creation (Galvagno and Dalli, 2014), marked by a lack of conceptual clarity between two perspectives; whether co-creation denotes the joint creation of services or the creation of value at a more abstract level (Mustak et al., 2013). This tension is apparent in the discourse between the S-D logic and its rival theories. The S-D logic insinuates that the customer is always a co-creator of value (Vargo and Lusch, 2004, 2008, 2016). Grönroos and co-authors developed a competing view; their service logic suggests that value co-creation occurs more specifically in the joint sphere of customer-provider interaction (Grönroos and Ravald, 2011; Grönroos and Voima, 2013).

Besides the debate on the conceptual clarification of co-creation, there is dispute on the forms of co-creation. While some publications implicitly assume that co-creation is the same as involvement, participation or co-production (Chang and Taylor, 2016; Dong and Sivakumar, 2017; Voorberg et al., 2015), other publications argue that the terms differ (Etgar, 2008; Grönroos and Voima, 2013; Lusch and Vargo, 2006). The inconsistent use of terms to signify the collaborative act in the customer-provider interface has led to conceptual pluralism in the service management domain. This can reduce consistency and decelerates the development of contributions to the topic.

Finally, existing conceptual overviews have not broadly analyzed and consolidated the potential, realistic outcomes of co-creating services (Voorberg et al., 2015). The interactive nature of services urges managers to understand co-creation to target the right customers and to recognize the expected benefits (Matthing et al., 2004). By co-creating services, service providers can realize beneficial outcomes, such as gaining a better understanding of their clientele, improving user-service fit and enhancing service performance (Dong et al., 2015; Edvardsson et al., 2013; Hoyer et al., 2010; Moeller et al., 2013). For example, DHL, the world's largest mail and logistics company, runs co-creation workshops with its customers. One of the solutions that emerged from this practice was the Parcelcopter, a drone that enables rapid delivery of parcels to geographically secluded areas that are challenging to reach for postal trucks, and thus improves the service experience for remote customers (Deutsche Post DHL Group, 2017; DHL Solutions \& Innovations, 2017).

Nonetheless, co-creation may also lead to counterproductive outcomes, such as uncertainty about service ownership and diminished efficiency and service performance (Carbonell et al., 2012; Dong and Sivakumar, 2015; Dong et al., 2015; Hurmelinna-Laukkanen and Ritala, 2010). Osei-Frimpong et al. (2015) suggested that successfully performed co-creation improves service outcomes, but unsuccessful executions can prompt value destruction. For example, the large German manufacturer Henkel ran an open co-creation contest to find a new label sticker for its Pril dish detergent, but the platform was engulfed by inappropriate propositions, such as "Pril tastes like chicken", which was voted as the top slogan by the online community (Gatzweiler et al., 2013; Verhoef et al., 2013). These counterproductive outcomes suggest that a comprehensive assessment of possible outcomes is vital for the successful management of co-creating services. 
JOSM

29,4

646

For the remainder of this paper, the authors focus on the second generation of customer-provider collaboration and direct the analysis toward a way that is meaningful for decision making in service management. In order to facilitate further theoretical and practical development, the co-creation of services includes frequent, bidirectional and transparent dialogue between customers and providers, is customer and experience centric, may occur in phases beyond service delivery and production, includes a diverse set of desired outcomes and is influenced by a multi-actor network.

Given the increasing number of contributions, the field needs integrative analyses to introduce conceptual coherence. Due to inconsistent use of terms and lack of shared definitions, comparing findings from the different studies on co-creating services is problematic. Despite that some literature reviews and several conceptual studies on co-creation of services have been published, conceptual inconsistency continues to exist in the research stream. Conceptual papers have explored the underpinning logic of co-creation (Grönroos, 2008, 2011, 2012; Grönroos and Ravald, 2011; Saarijärvi et al., 2013; Vargo and Lusch, 2008), the interrelation between co-creation and other terms, such as co-design and co-production (Chathoth et al., 2013; Lusch and Vargo, 2006; O'Hern and Rindfleisch, 2010) and the embeddedness of co-creation in social service systems (Edvardsson et al., 2011; Maglio and Spohrer, 2008; Vargo et al., 2008).

Existing reviews concentrate on classifying and synthesizing the diverse disciplinary roots of co-creation (Galvagno and Dalli, 2014; Greenhalgh et al., 2016; Ind and Coates, 2013; Ranjan and Read, 2016) and on developing co-creation models for different business modes and industries (Greenhalgh et al., 2016; Romero and Molina, 2011). Out of the six reviews identified, only Voorberg et al. (2015) focused on the outcomes following co-creation. However, their examination of co-creation outcomes is limited to the context of citizen participation in public innovation, inviting further explorations on the outcomes of co-creation in the service industries more broadly.

Regarding methodological choices, existing co-creation reviews use search strategies based on pre-set search terms to identify the literature using search engines: Galvagno and Dalli (2014) used "co-creation"; Voorberg et al. (2015) used "co-creation" and "co-production"; and Ranjan and Read (2016) added "value-in-use" to these search terms. Other reviews on related terms have also included "co-creation" as a search term, for example, Dong and Sivakumar (2017) searched for "participation," "co-production" and "co-creation" in their customer participation review and Chang and Taylor (2016) used "participation," "involvement," "co-production," "crowdsourcing" and "co-creation" in their meta-analysis on customer participation. Both the diversity of the pre-set search terms used for systematic analyses and the increasing number of conceptual contributions on the interrelations between co-creation and related terms highlight the existing debate on the forms of co-creation (Etgar, 2008; Galvagno and Dalli, 2014; Grönroos and Voima, 2013; Payne et al., 2008; Saarijärvi et al., 2013; Voorberg et al., 2015). A gap remains in differentiating, synthesizing, explicating and organizing the terminology on the forms of service co-creation. To address this gap, the current effort follows an inductive and inclusive approach, allowing the terminology that addresses the collaborative act between customers and providers to emerge inductively through a focused literature review.

\section{Review approach}

In response to the research questions, this paper implements a systematic yet focused literature review approach. Focusing on the service research literature, its main purposes are: to assess, clarify and consolidate the terminology around the co-creation of services and to assess and consolidate the forms and outcomes of co-creating services. By taking an inductive and inclusive approach, allowing similar and neighboring terms to emerge from the literature set, this focused review seeks to disentangle the body of knowledge related to co-creating services and to reduce the existing conceptual pluralism. Because many relevant publications use other labels than co-creating services to denote forms of collaborative creation, using a pre-set keyword search 
would diminish the richness of the relevant co-creation terminology to be discovered by limiting the analysis to those studies that specifically mention the term. The focused literature review of all articles published in five service journals included the Journal of Service Management, Journal of Services Marketing, Journal of Service Research, Journal of Service Theory and Practice and Service Industries Journal. Three criteria drove the selection of these journals: first, each journal had to be rated by the SSCI (Thomson Reuters, 2015); second, only journals focusing on services are included; and third, the journals are inclusive and generic service journals and not specific to any particular industry (e.g. healthcare).

While not exhaustive in terms of publication outlets, this review provides a lens to focus on the developments in co-creating services, specifically in the service literature, which is essential given the current confusion with regard to conceptualizing co-creation (Dong and Sivakumar, 2017; Grönroos and Ravald, 2011; Saarijärvi et al., 2013) and calls for more research on the outcomes of co-creating services (Voorberg et al., 2015). The five publication outlets published 2,466 articles between January 2006 and August 2016-a time frame that included the appearance of most co-creation articles (Galvagno and Dalli, 2014). The body of the current theorizing emerged from this set of articles through inductive analysis proceeding in stages, beginning with the analysis of the abstracts of all published articles. To include earlier years, the authors conducted a supplementary SCOPUS search in the five publication outlets of all years before 2006, using all terms identified in the previous analysis as search terms beside co-creation.

To ensure an appropriate structure and objectivity in the selection of literature, the focused literature review followed the four consecutive stages proposed by Booth et al. (2016): literature search, appraise the evidence base, analyze the findings and synthesize the results. To extend coverage in time, a fifth stage that comprised the supplementary SCOPUS analysis of articles prior to 2006 was added. Table II provides an overview of the activities during each of the stages.

Stage 1 included an initial inspection of the titles, keywords and abstracts that were accumulated during the literature search. During this first review, publications were included in the set for the next review step if the focal concept co-creation/cocreation of services was present and the paper included content focusing on outcomes of co-creation; or other relating terms that pointed to collaborative customer-provider creation were identified, including its outcomes; or the publications clearly reflected the results of customer-provider co-creation despite lacking a specific keyword pointing to co-creation. If any ambiguity was perceived, the whole publication was skimmed to determine suitability. Stage 1 resulted in a set of 138 articles.

In Stage 2, the introduction, literature review and methodology sections of the articles were examined. In this inspection, 54 articles were excluded for three reasons. First, scrutinizing several conceptualizations in more detail led to the exclusion of studies that did not relate to collaborative co-creation in practice, such as the customer empowerment study by O'Cass and Ngo (2011). Second, the search targeted co-creation of services in the customer-provider interface, but several articles examined co-creation between employees or firms instead (e.g. Mukherjee and Malhotra, 2006). Third, some articles featured related terms that incorporated meanings different from co-creating services, such as the involvement definition by Zaichkowsky (1985) that presents involvement as the person's perceived relevance of an object; mere perception of relevance lacks the collaborative aspect in service co-creation. Thus, 84 articles remained for further analysis.

The inspection during Stage 3 included reading of the analysis, results and discussion sections, following the sequence of their assigned numbers. Ten articles were omitted from further analysis because they did not specify service co-creation outcomes for the customer or the service provider. Stage 3 resulted in the final set of 74 articles.

The fourth stage contained the synthesis of the findings, which is presented in the following four sections. Section 3 introduces the identified terminology associated with co-creation in services. Section 4 comprises a thematic analysis of the forms and themes of extant conceptualizations discovered in the 80 articles and develops an explicit definition of co-creating services. 
JOSM

29,4

\section{8}

\section{Table II.}

Overview of the focused literature review process

\section{Research procedures}

Stage 1:

Five target journals: Journal of Service Management, Journal of Services Marketing, identification and Journal of Service Research, Journal of Service Theory and Practice and Service screening of Industries Journal

abstracts

Time frame: January 2006-August 2016, containing 2,466 articles

Initial inspection based on title, keywords and abstract: an article was included, if it addressed some form of collaborative act in the customer-service provider interface and indicated that some kind of outcome(s) resulted from this co-creation. Articles that discussed value co-creation on an abstract level, without addressing a service event or episode that yielded some kind of outcomes or consequences from the co-involvement of the customer and the service provider, were excluded from the literature set

If ambiguity prevailed during the initial inspection, the whole publication was skimmed for its suitability

Citation management software (EndNote X7) was used to store and explore the literature effectively

A single line was written about each publication and its relation to the outcomes of co-creating services to attain a reference point

Result: 138 articles
Stage 2:

screening and analysis of article content

Stage 3: screening and analysis of the findings

Stage 4: synthesizing the findings

Stage 5: supplementary SCOPUS search
Secondary inspection of articles, arranged in chronological order, based on reading the introduction, literature review and methodology parts

For each article, the definitions, explanations and descriptions of "co-creating services" were entered into a spreadsheet file

During this closer inspection of the article content, the articles were excluded for the following reasons: (a) co-creation was not addressed; (b) co-creation was addressed, but not between the customer and the service provider; and (c) words interpreted as terminology typically associated with co-creation of services were used in in another meaning or context

Result: 84 articles

Tertiary inspection based on reading the analysis, results and discussion sections of all articles in sequence of their assigned numbers

Following the tertiary inspection, 10 articles were excluded for the following reasons: (a) no outcomes of co-creating services addressed; or (b) has outcomes of co-creating services, but not for the customer or the service provider Result: 74 articles

Section 3: Discussion on the terminology determined through the focused review found to be related to co-creating services

Section 4: Explicit definition of co-creating services based on thematic analysis of the forms and themes of extant conceptualizations Section 5: Typology of the beneficial and counterproductive customer and provider outcomes of co-creating services based on thematic analysis of the outcomes and classified after the co-creation experience dimensions of Verleye (2015) Section 6: Integrative framework for the co-creation of services based on the prior review findings and the comparison between the different terms

SCOPUS search of all targeted publication outlets of the years before 2006

Searched keywords: co-creation/cocreation OR involvement, engagement, participation, co-design/codesign, co-production/coproduction, co-consumption/coconsumption, pro-sumption/prosumption, AND outcome

The SCOPUS search identified 14 articles of which six articles passed the screening (as above) and were added to the data set and syntheses of Stage 4 Result of supplementary review: 6 articles added, total 80 articles 
Further thematic analysis of the outcomes in Section 5 then provides a typology of beneficial and counterproductive customer and service provider outcomes of co-creating services, classified according to the co-creation experience dimensions of Verleye (2015) and discusses how the terminology of co-creating services differs across the outcomes. Finally, Section 6 develops an integrative framework capturing the identified co-creation forms and outcomes.

In the last stage, to develop a comprehensive picture of the development of the co-creation theme in the five journals, the researchers performed a focused, supplementary SCOPUS search to cover the relevant articles published before 2006. As the searched keywords the authors used the terms that had emerged in the analysis, introduced in Section 3, and the word "outcome" to ensure that all publications included both co-creation of services and addressed consequent outcomes. Six articles passed the screening, growing the data set from 74 to 80 articles and were further included in the syntheses of Stage 4.

Before entering the in-depth conceptual review findings, a brief overview of the reviewed studies is provided here in the form of descriptive statistics. Table III demonstrates how the identified co-creation literature spreads across the five journals. Figure 1 shows the total number of co-creation articles published per year (full years only). Table IV presents the methodological orientation of the articles, showing that 95 percent of the reviewed articles are empirical research.

\begin{tabular}{|c|c|c|}
\hline Journal & Number of publications & Percentage \\
\hline Service Industries Journal & 21 & 26.25 \\
\hline Journal of Service Management ${ }^{\mathrm{a}}$ & 19 & 23.75 \\
\hline Journal of Service Research & 15 & 18.75 \\
\hline Journal of Services Marketing & 14 & 17.50 \\
\hline Journal of Service Theory and Practice & 11 & 13.75 \\
\hline Total & 80 & 100 \\
\hline
\end{tabular}

Notes: ${ }^{a}$ Previously published as International Journal of Service Industry Management, ${ }^{b}$ previously published as Managing Service Quality

Co-creating services

649

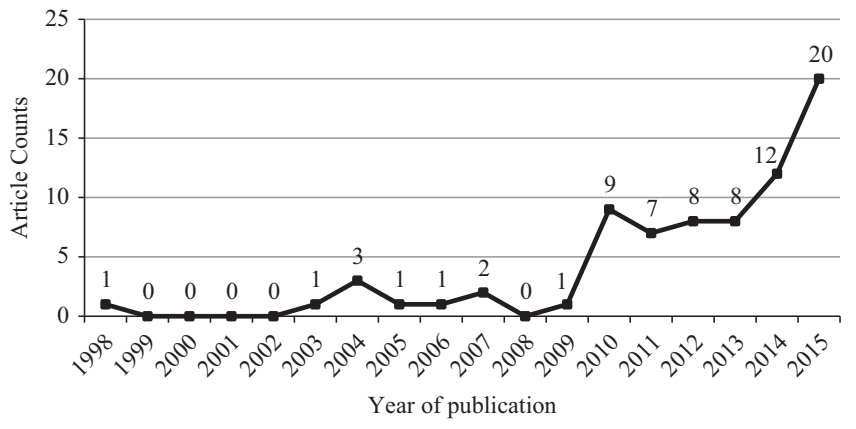

Figure 1.

Number of reviewed articles published per year

\begin{tabular}{lcr}
\hline Research approach & Number of publications & Percentage \\
\hline Conceptual & 4 & 5.00 \\
Empirical & 76 & 95.00 \\
Qualitative & 23 & Table IV. \\
Quantitative & 38 & Methodological \\
Mixed & 15 & orientation of the \\
Total & 80 & reviewed studies \\
\end{tabular}


JOSM

29,4

650

\section{The concept of co-creating services and related terminology}

In response to the first research question, the focused literature review identified several terms that subject to a similar meaning as the co-creation of services. The terms that appeared most frequently in the reviewed 80 articles are co-creation (e.g. Russo-Spena and Mele, 2012; Witell et al., 2011), involvement (e.g. Carbonell et al., 2012; Cheng et al., 2012), engagement (e.g. Jahn and Kunz, 2012; O'Brien et al., 2015), participation (e.g. Dong and Sivakumar, 2015; Engström and Elg, 2015), co-design (e.g. Gebauer et al., 2010; Quero and Ventura, 2015), co-production (e.g. Guo et al., 2013; Mende and van Doorn, 2015) and co-consumption/prosumption (Quero and Ventura, 2015; Witell et al., 2011). Other terms brought up in the literature, although less frequently, are servuction (Gebauer et al., 2010), collaboration (Ordanini and Parasuraman, 2011), interaction (Alam, 2011) and cooperation (Hsieh et al., 2013).

When scrutinizing the literature of the focused review and of other reviews on the topic, it becomes apparent that there is much debate on the terminological relatedness between the terms. Some authors treat the terms as inclusive, such as when Dong and Sivakumar (2017) suggested using customer participation to encompass co-production and co-creation; Gebauer et al. (2010) proposed that co-creation integrates salient aspects of co-production; Russo-Spena and Mele (2012) depicted co-creation as an overall concept for customer involvement; and Chang and Taylor (2016) implicitly recognized co-creation, co-production and customer involvement as synonyms for customer participation and included them as equal search criteria in their meta-analysis. In their systematic review, Voorberg et al. (2015) showed that researchers often use co-creation and co-production interchangeably. Similarly, Dong and Sivakumar (2017) demonstrated how a multitude of terms have been used to describe customer participation, such as customer engagement, co-production and co-creation, and Mustak et al. (2013, p. 354) denoted co-design, co-development and customer engagement as "other terminology to study the same subject [customer participation]."

This interchangeable use of terms has led to increasing confusion about their conceptual content and blurred the resulting analyses and outcomes. To reduce this misperception, many authors have tried to disentangle the terminology. For example, Dong and Sivakumar (2017) recognized that co-creation, customer participation and co-production belong to the same meaning cluster, while they differentiated customer engagement and customer innovation as related but distinct terms. Regarding customer participation in co-creation, Mustak et al. (2013) differentiated between participation in creating offerings and participation in creating value. Lusch and Vargo (2006) also described two components of co-creation: co-creation of value and co-production. The first is more encompassing and can be determined only by the customer during the consumption process, whereas the latter denotes participation through co-design or shared inventiveness in creating the offering. Similarly, in Etgar's (2008) model of consumer engagement in co-production, co-creation of value occurs in the consumption stage, but co-production happens during the production process, before usage. Finally, Grönroos and Ravald (2011) and Grönroos and Voima (2013) argued that through interaction in a joint creation process, the customer can get involved as a co-designer, co-developer and co-producer in the service provider's processes, while the service provider can participate as a value co-creator in the customer's processes.

This paper suggests that none of the terms are direct synonyms for co-creating services, but that involvement, engagement and participation act as necessary prerequisite-forms (in short, prerequisites) for the co-creation of services to occur. Co-design, co-production and co-consumption are considered specific forms of the co-creation of services that further describe in which phase of the service process co-creating services is taking place. Consider DHL's co-creation workshops with customers as an example: Customers and DHL employees must be involved in the workshop to take part in co-creating services; actively participate in service co-creation; and finally, be engaged cognitively, behaviorally or affectively (or all at once) before they can be prompted to co-create. Once these prerequisites are fulfilled, customers 
jointly collaborate with $\mathrm{DHL}$ in a process of co-creation; specifically, they co-design solutions during the design and development phases (DHL Solutions \& Innovations, 2017).

In an attempt to clarify the concept of co-creation of services and disentangle the conceptual pluralism surrounding it, the following sections compare and contrast the different associated terms based on the 80 articles accumulated through this focused review.

\section{Defining the co-creation of services}

In response to the second research question, the authors conduct a thematic analysis of the forms and themes of co-creating services that aims to pinpoint and understand where and how service literature converges and diverges (Green et al., 2017). A thematic analysis is a theoretically flexible approach that enables the identification and description of patterns within a literature stream (Braun and Clarke, 2006; Fereday and Muir-Cochrane, 2006). As a first step in moving toward a definition of the co-creation of services, emerging themes in existing conceptualizations enabled the authors to provide new clarity about the phenomenon of co-creating services. Then, the researchers could synthesize and translate key themes in the different conceptualizations, even if they were expressed using different wording (Thomas and Harden, 2008). The thematic analysis involved careful reading and re-reading of the identified conceptualizations of co-creating services, as summarized in Table V. The label "term" (Column 1, Table V) refers to the seven terms that relate to the co-creation of services (co-creation, involvement, engagement, participation, co-design, co-production and co-consumption). The label "conceptualization of the term" (Column 2) indicates which one of the seven terms in Column 1 is cited by the conceptualization in a particular publication. The different "themes within the conceptualization" (Columns 4-10) provide an overview; these themes may or may not be captured by a specific conceptualization. The following paragraphs explain the procedure of the thematic analysis in more detail.

First, the authors identified which of the selected articles in the focused review provide a conceptualization related to the co-creation of services. Of the 80 articles selected, 51 articles provide 63 conceptualizations that are coded into seven categories depicting a concept or a term: co-creation, involvement, engagement, participation, co-design, co-production and co-consumption/pro-sumption. In total, 29 publications that addressed the collaborative act in the customer-service provider interface do not conceptualize specific terms or their terms occur only infrequently within all selected articles, such as customer cooperation by Hsieh et al. (2013) or collaboration by Ordanini and Parasuraman (2011). Especially for cooperation and collaboration, the low number of conceptualizations is likely because the terms are used rather unconsciously and are often not further delineated. The reliability of coding the 63 conceptualizations into their respective terms was evaluated using Cohen's Kappa $\kappa$. The resulting $\kappa=1$ implied perfect interrater agreement across the author team (Landis and Koch, 1977). Although the 51 articles provided 63 conceptualizations, not all articles proposed new definitions; some relied on previous works. For example, Edvardsson et al. (2013), Elg et al. (2012) and Melton and Hartline (2015) all cited Witell et al's (2011) definition. Yet, no conceptualization appears more than four times across the set of articles, confirming the conceptual fragmentation and need for a consolidating definition.

Second, these conceptualizations were coded according to seven emerging themes, as detailed in Table VI. The seven themes (Columns 4-10, Table V) were derived by reading and re-reading all 63 conceptualizations for any common wording or meaning. For example, "joint," "customer" and "actor" appear multiple times, as do phrases related to the service process, such as "ideation," "design," "development" and "delivery." Using this common wording or meaning, the authors then developed the different themes. For the assessment of the inter-rater reliability of coding the conceptualizations into the seven themes, the Cohen's $\kappa$ value was 0.71 , which denotes substantial agreement across the author team (Landis and Koch, 1977). Disagreements were mostly due to language misunderstandings, so they could be resolved by refining the choice of wording of the themes. 


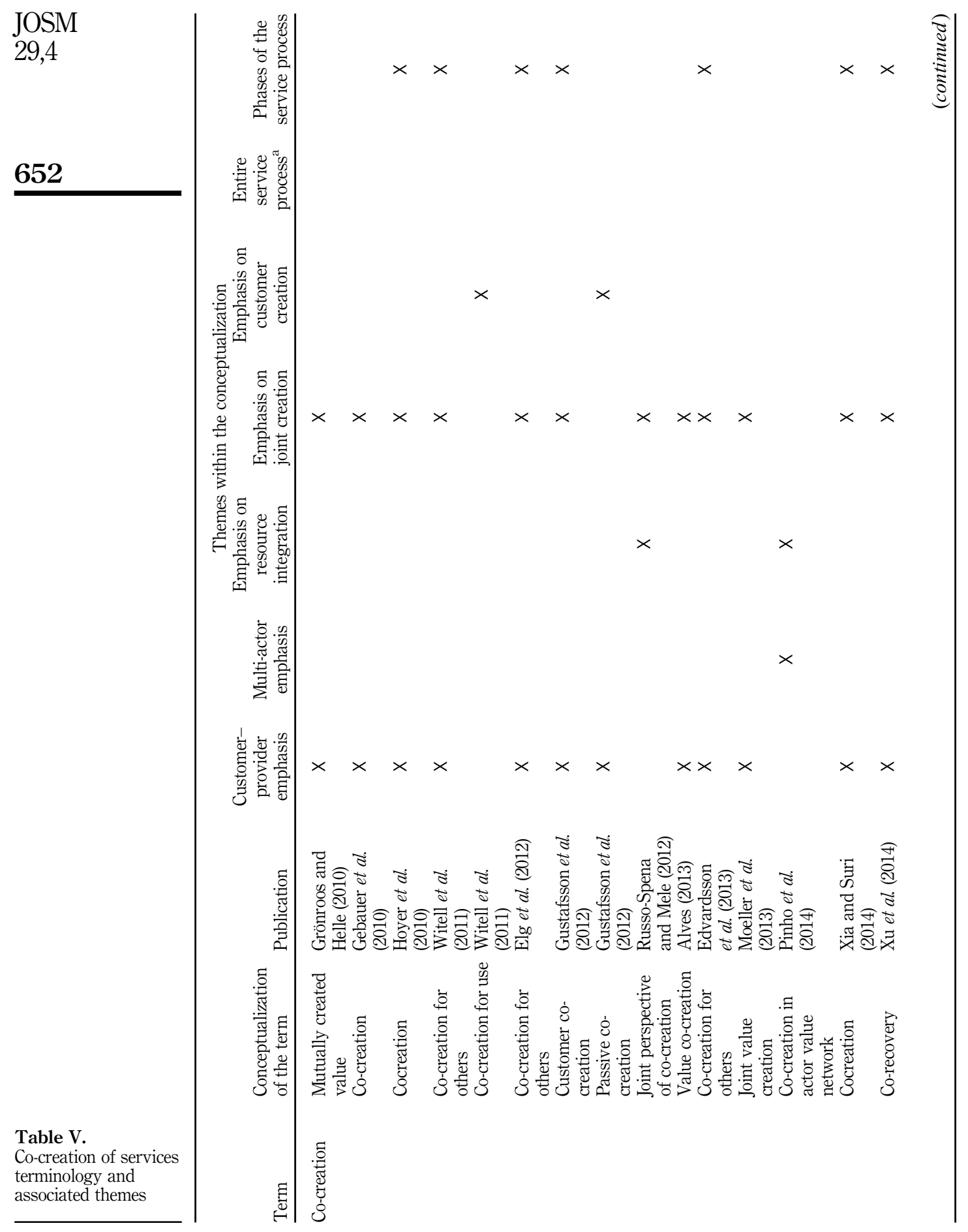




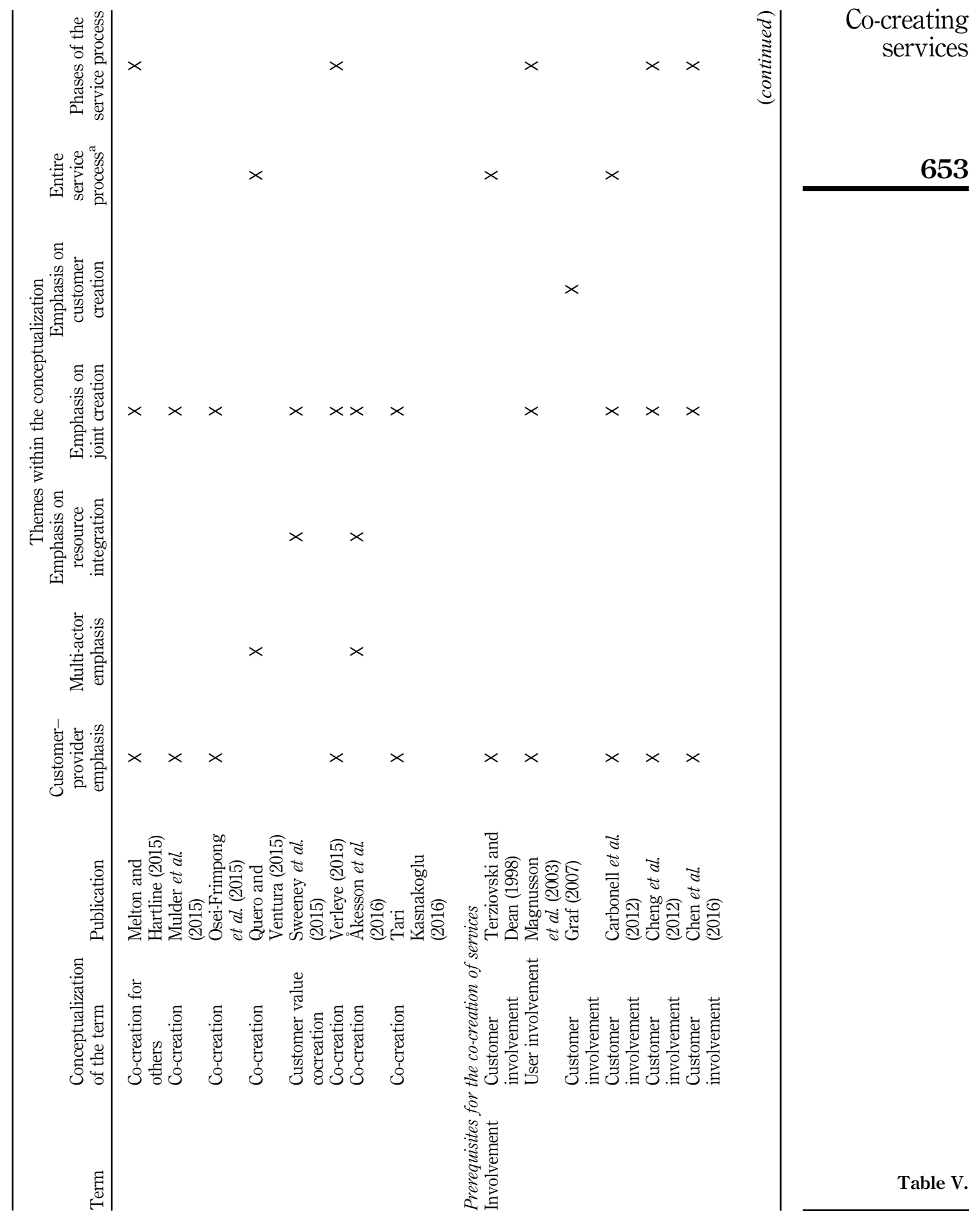




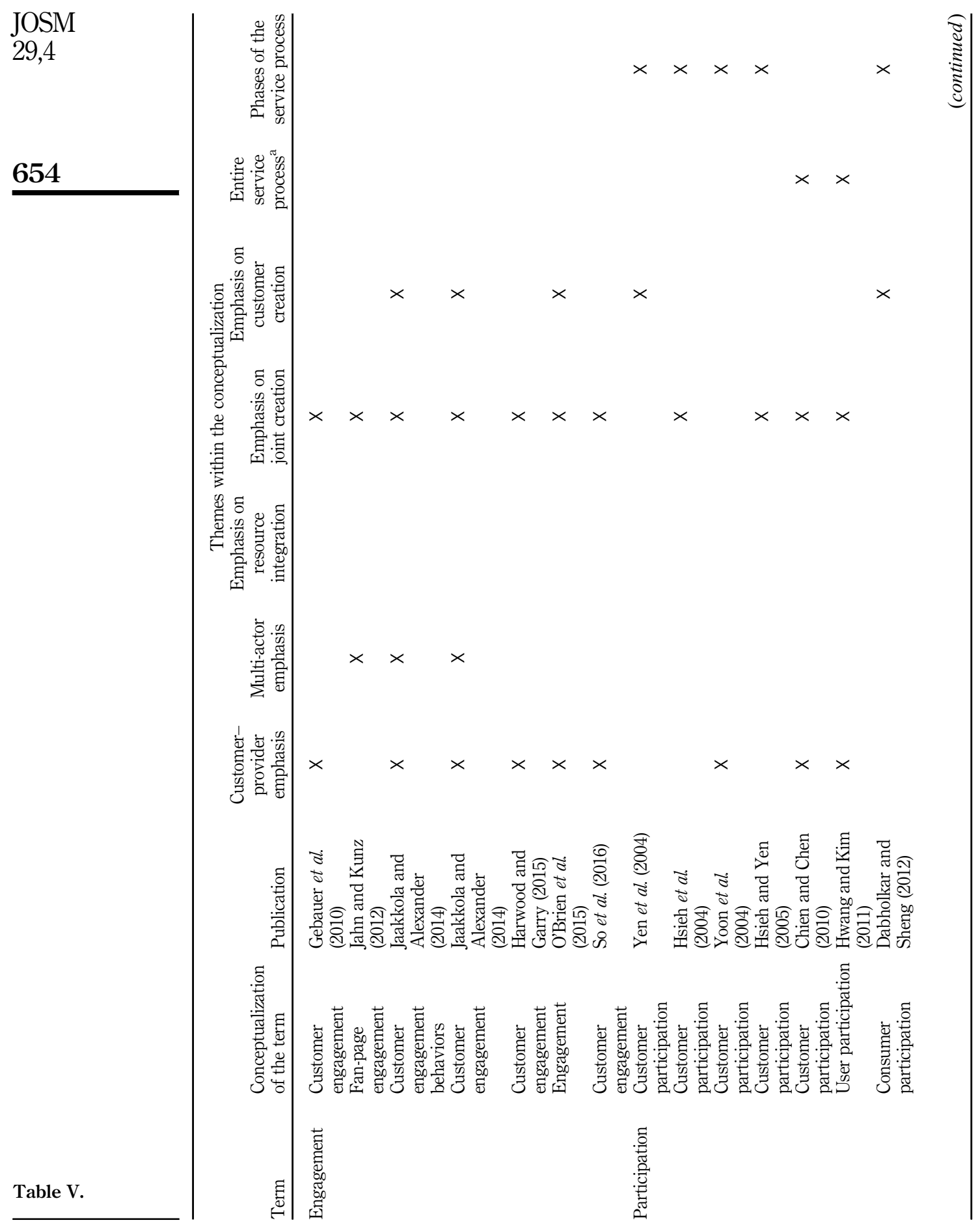




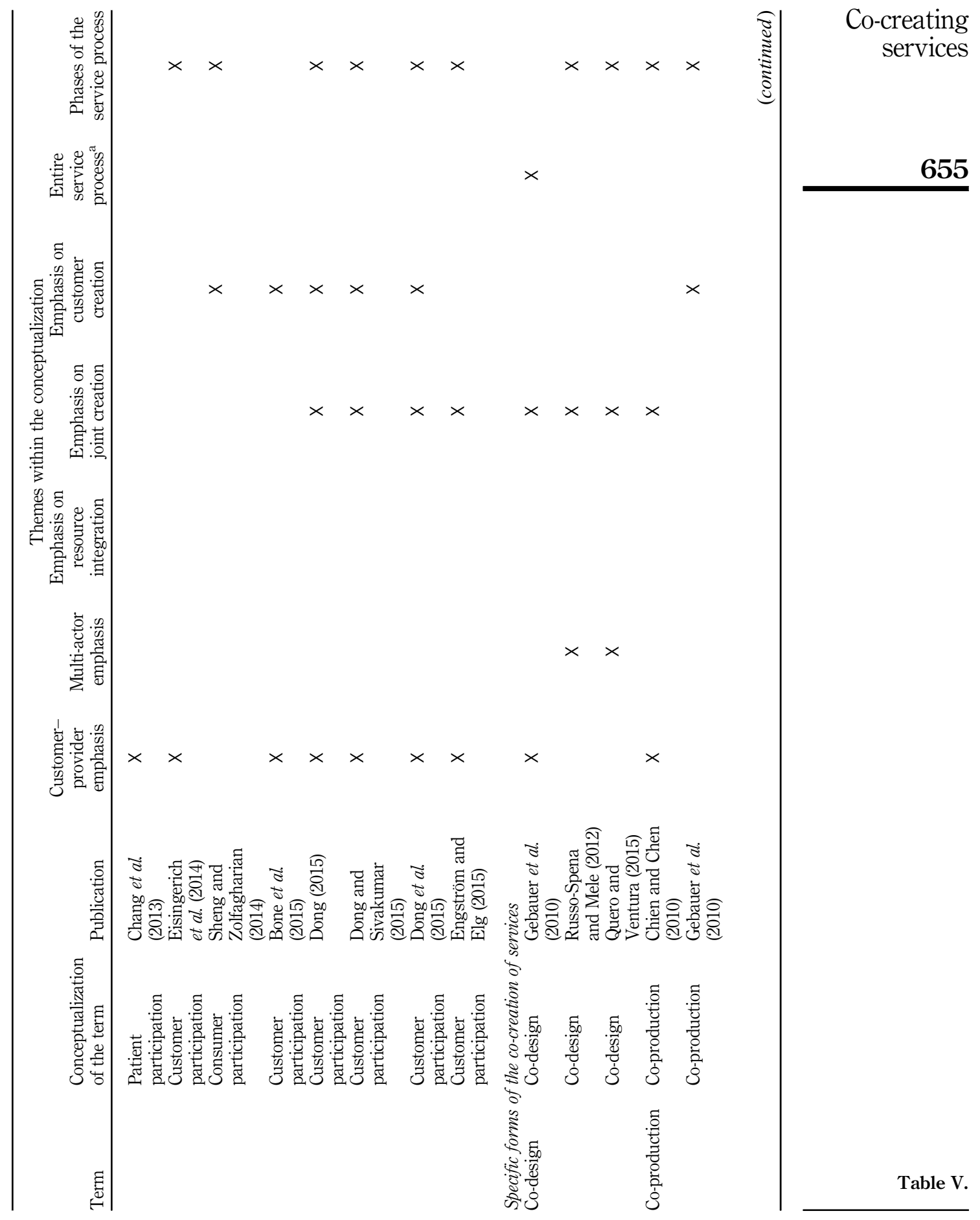


JOSM

29,4

656

Table V. 
Theme

Explanation

Customer-provider emphasis

Multi-actor emphasis

Emphasis on resource integration

Emphasis on joint creation

Emphasis on customer creation

Entire service process

Selected phases of the service process
The conceptualization focuses on the collaborative act between the customer and the service provider and does not specifically name other actors

The conceptualization focuses specifically on more actors than just the customer and the service provider

The concept of resource integration is mentioned within the conceptualization

Co-creating services occurs on a joint interface through a collaborative act Co-creating services occurs on the customer's side throughout the customer's own actions and implicates less direct collaboration with the service provider Co-creating services takes place during the entire service process, denoting all phases such as co-ideation, co-valuation, co-design, co-testing, co-launching, co-production and co-consumption of a service

The conceptualization specifically mentions co-creating services taking place in a particular phase of the service process, for instance in the co-design or co-consumption phase
Co-creating services

657

Table VI.

Explanation of the seven emerging themes in co-creation of services conceptualizations

Third, the prevalence of each theme, in terms of its absolute number of occurrences, provides the basis for introducing an explicit definition of co-creating services grounded in extant insights. The findings demonstrate a strong emphasis on customer-provider mutual creation, which is not surprising, considering the selection criteria of the focused review. However, the findings also reveal a growing focus on the influence of a multiactor context (Åkesson et al., 2016; Pinho et al., 2014). This finding is in line with the authors' presentation of the first and second generation of customer-provider collaboration. Initially, the customer-provider dyad was in the focus, which has shifted toward including the influence of a multi-actor network. Some authors cite resource integration (Pinho et al., 2014; Russo-Spena and Mele, 2012; Sweeney et al., 2015), but most conceptualizations have not adopted this specific term, yet. According to the S-D logic, when resources are integrated, value gets co-created (Vargo and Lusch, 2008), which is an implication similar to the contribution of information by customers (Chang et al., 2013; Witell et al., 2011) or support received from the physical labor of other actors (Dong, 2015) in the co-creation of services. The analysis also reveals an emphasis on joint creation, contrary to mere customer creation, which reflects the focus of the second generation of customer-provider collaboration on the frequent, bidirectional and transparent dialogue between the customer and provider in a joint interface (Chathoth et al., 2013; Gustafsson et al., 2012; Prahalad and Ramaswamy, 2004a).

Many studies concentrate on co-creating services during selected phases of the service process (Russo-Spena and Mele, 2012). This research labels these terms as specific forms of co-creating services. Such specific forms of co-creating services, either as new, revised, repeated services or even innovations, include the co-ideation phase (Moeller et al., 2013), co-valuation and co-design phase (Hsieh et al., 2013), co-test and co-launch phase (Xia and Suri, 2014), co-production phase (Chen et al., 2015) and co-consumption phase of a service (Quero and Ventura, 2015). Because all phases are included, this analysis indicates that co-creating services can, but does not have to, manifest itself in all phases of the service process. Based on this thematic analysis, the authors identify an explicit definition of co-creating services, as follows:

The co-creation of services denotes collaborative activities in the customer-provider interface associated with the service; it necessitates the involvement, engagement and participation of at least one customer and one service provider and may lead to beneficial and/or counterproductive outcomes through resource integration. In services, co-creation manifests itself in different forms depending on the phases of the service process (co-ideation, co-valuation, co-design, co-test, co-launch, co-production and co-consumption) and is influenced by a contextual, multi-actor network. 
JOSM

29,4

\section{8}

Figure 2.

Themes of the thematic analysis represented across the co-creation of services terminology
During the thematic analysis, the authors further compared and contrasted the terms associated with co-creating services. Figure 2 depicts the percentage scores for the identified terminology across the seven themes discovered and Table VII summarizes these values as low-, medium-, and high-emphasis categories.

The co-creation terms are associated with the theme of customer-provider emphasis, with the exception of pro-sumption or, as Quero and Ventura (2015) named it, co-consumption. The three studies on co-consumption focus on specific phases rather than the whole service process, because co-consumption predominantly occurs during the use phase. Co-consumption and pro-sumption refer to "collaboration for use and consumption" (Quero and Ventura, 2015, p. 125). Literature covering specific phases of the service process further emphasizes co-design and co-production terms, in addition to referring to coconsumption (Chien and Chen, 2010; Quero and Ventura, 2015; Russo-Spena and Mele, 2012). In contrast, the phases of the service process receive little mentioning by literature that uses co-creation, involvement and engagement terms. This finding supports the authors' reasoning that co-design, co-production and co-consumption are specific forms of the co-creation of services as they manifest themselves during particular phases of the service process.

Literature exploring the co-consumption term emphasizes the consumption and use phase and pays less attention on customer-provider collaboration theme; instead, the studies addressing co-consumption focus on customer creation. Witell et al. (2011) suggested that the term focuses on customers' creation activities that lead to the production of offerings, which they finally consume; hence, they focus on the customer's side. The theme of customer creation also contains studies using the terms engagement and participation, but unlike studies on co-consumption, engagement and participation studies emphasize the customer-provider theme. The notion of multiple actors in the collaborative act is mostly emphasized by studies using the terms co-design and engagement, highlighting other actors beyond the dyadic customer-provider collaboration. As Quero and Ventura (2015, p. 125) explained, co-design "encompasses a wide range of practices based on the engagement of many actors linked by a shared context and interest."

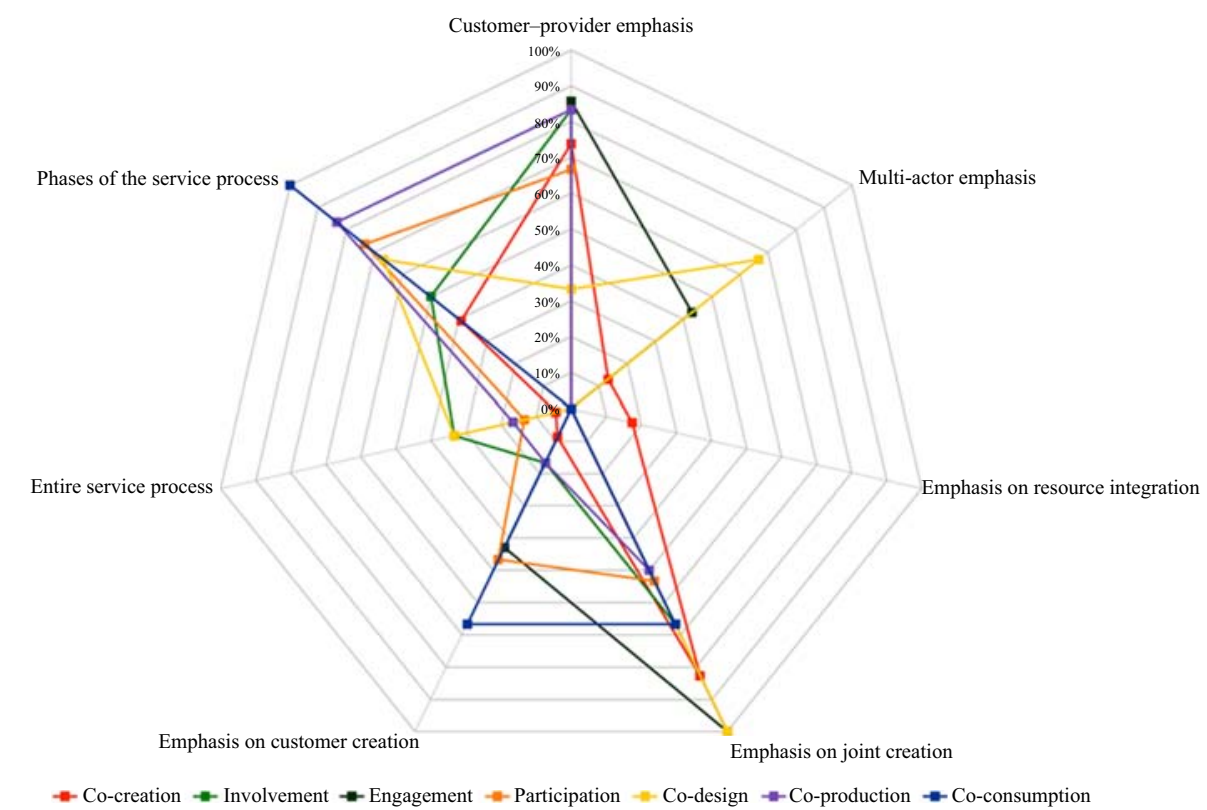




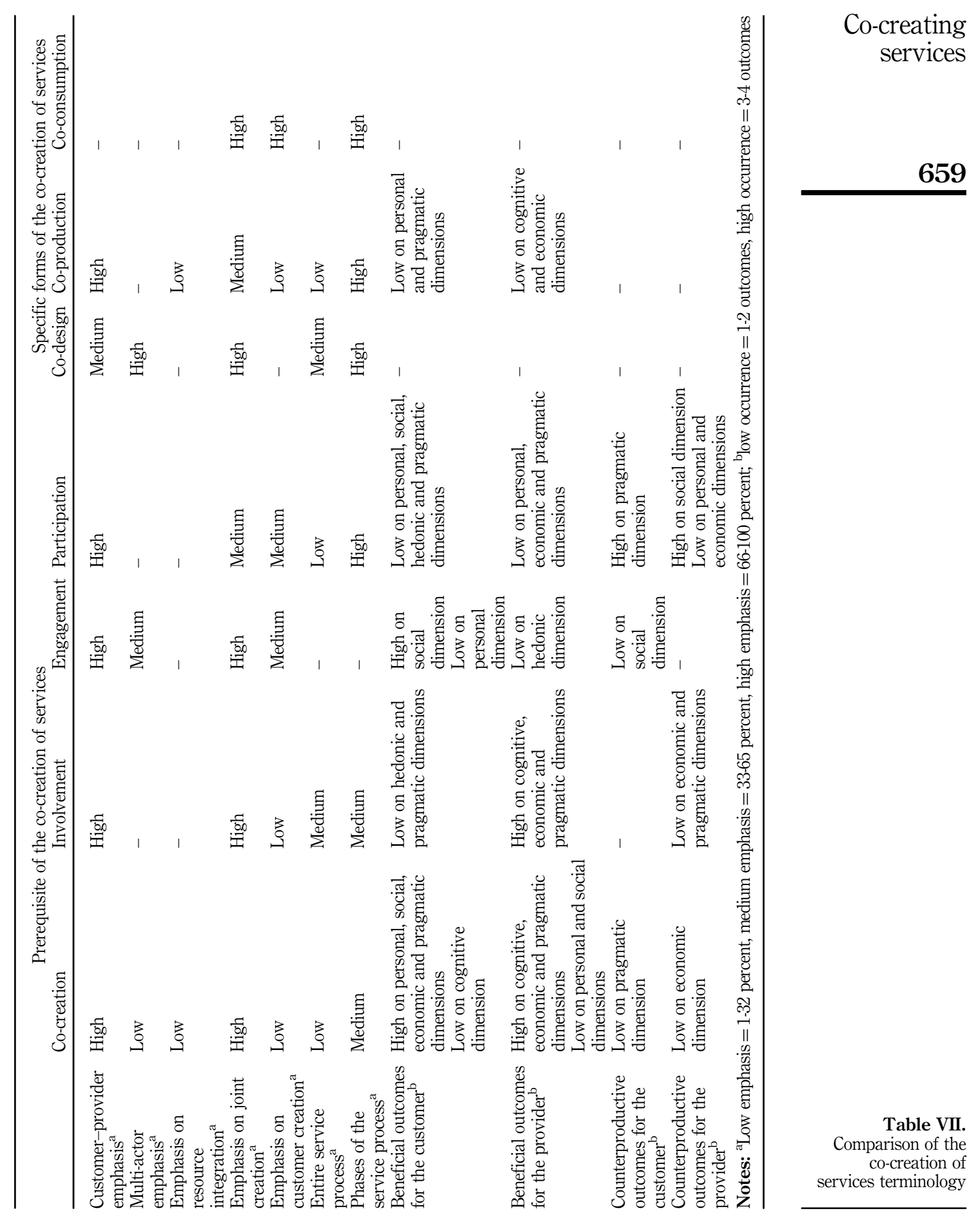


JOSM

29,4

660

Finally, all themes share the following three observations. First, co-creation is the only term that is frequently used in all seven themes, underlining both the versatility and the overarching nature of the term. Second, although the idea of resource integration has been advocated in some articles on co-creation, this theme draws only limited and sporadic attention (cf. Ảkesson et al., 2016; Pinho et al., 2014) across the literature suggesting the different co-creation terms. Third, the theme that emphasizes joint creation is common across the entire terminology; this expresses the frequent, bidirectional and collaborative nature of co-creating services. Due to the recurrent emphasis of involvement, engagement and participation terms on the joint customer-provider creation, the authors feel further supported in their claim that these three terms are necessary prerequisites for co-creating services, as without them no collaboration between service providers and customers is realizable.

\section{A typology of outcomes from co-creating services}

To address the third research question, the study develops a typology of outcomes that result for both customers and service providers from co-creation in service provision. This typology synthesizes Verleye's (2015) research on customer benefits that result from co-creating the service experience with further observations rooted in the current focused review. Analyzing expected benefits from co-creation, Verleye (2015) identified six co-creation experience dimensions that influence the overall co-creation experience, defined as follows: personal benefits: "gaining a better status and recognition"; social benefits: "being able to connect with other people"; hedonic benefits: "having pleasurable experiences"; cognitive benefits: "acquiring new knowledge/skills"; economic benefits: "compensation in line with effort made"; and pragmatic benefits: "solutions better meeting personal needs" (Verleye, 2015, pp. 323-324).

To construct the typology of co-creation outcomes for the current study, the authors used these co-creation experience dimensions as a foundation for the thematic analysis that categorizes the varying outcomes of co-creating services. Given the current focused review approach, discussions on more generic types of service outcomes, common in the broader service literature beyond the co-creation theme, are not included-naturally, all service events should lead to the fulfillment of the value proposition and, subsequently, capture some intended economic or non-monetary value for the provider.

First, in the 80 articles included, 171 individual observations capturing a broad range of co-creation outcomes were identified. Second, the observations were sorted using Verleye's (2015) co-creation experience dimensions. Third, as the observations included both positive and negative attributions, they were sorted to beneficial and counterproductive outcomes, respectively. Fourth, each observation was sorted in terms of its beneficiary, i.e., whether the outcome addressed the customer or the service provider. Finally, Verleye's (2015) dimensions were further developed by clustering the observations within each dimension. For example, the personal benefits for the customer include recognition, self-esteem, well-being, quality of life perception and empowerment and ownership; all these concepts represent "gaining a better status and recognition" (Verleye, 2015, p. 324). Illustrated with selected quotations from the literature, Table VIII presents the typology of the beneficial and counterproductive outcomes of co-creating services for the customer and the service provider.

Table VIII reveals that for customers, scholarly contributions emphasize personal, social and pragmatic benefits. Hedonic, cognitive and economic benefits have received less attention, both in terms of absolute number of references and outcome diversity. For personal benefits, previous publications highlight customers' well-being, especially in terms of financial well-being (Guo et al., 2013; Mende and van Doorn, 2015). Customers' social benefits, such as the ability to connect with other people, predominantly appear as loyalty with the service provider (Harwood and Garry, 2015; O'Brien et al., 2015) and positive word-of-mouth (intentions) (Ferguson et al., 2010; Tari Kasnakoglu, 2016). The hedonic benefits acknowledge enjoyment and fun as 


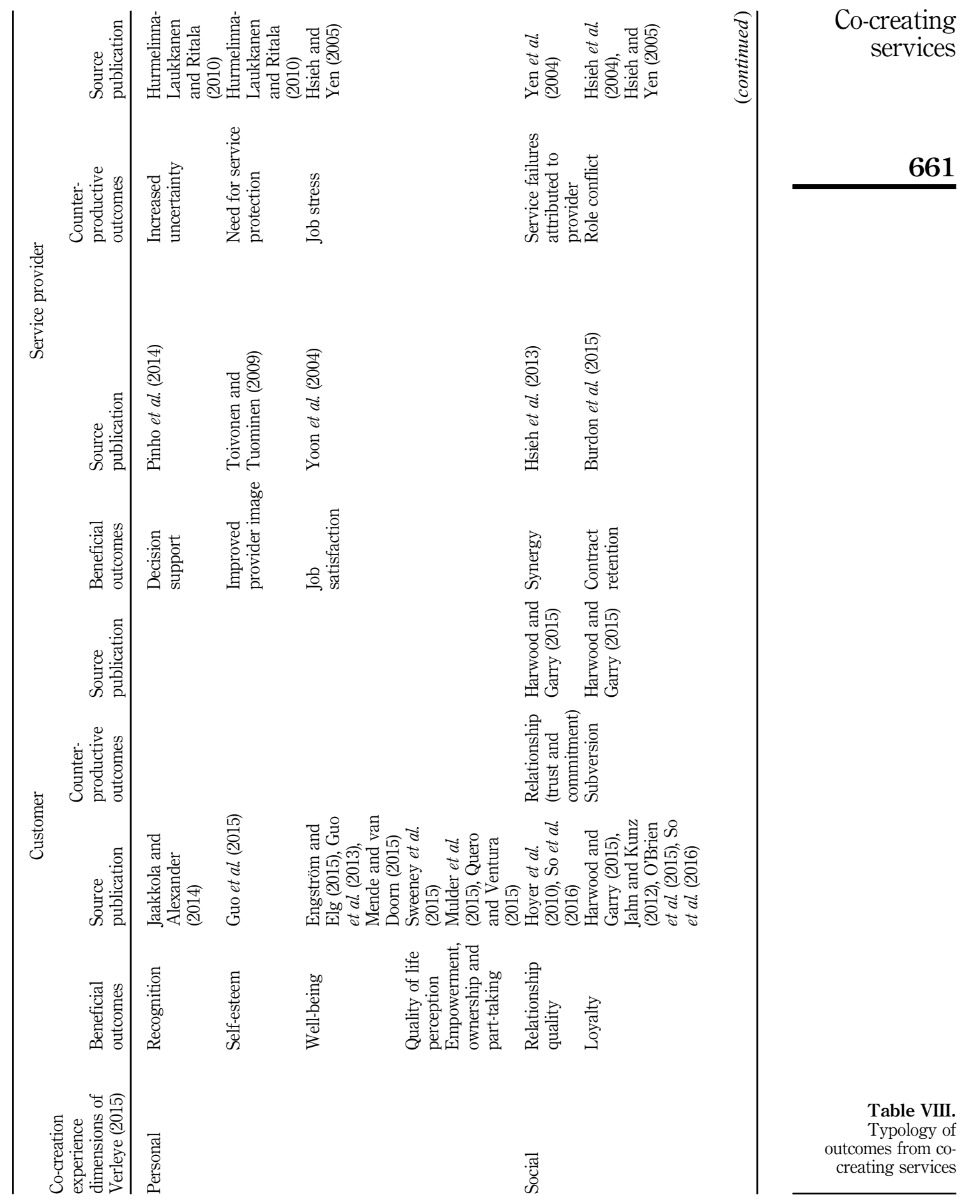


\begin{tabular}{l} 
JOSM \\
29,4 \\
662 \\
\hline
\end{tabular}

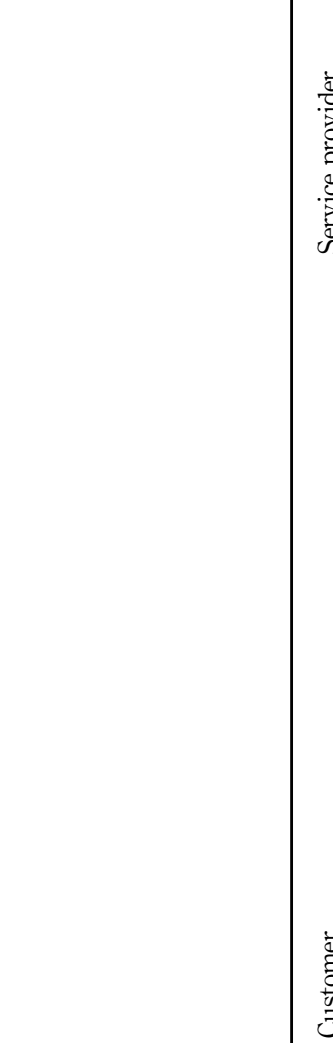

Table VIII.

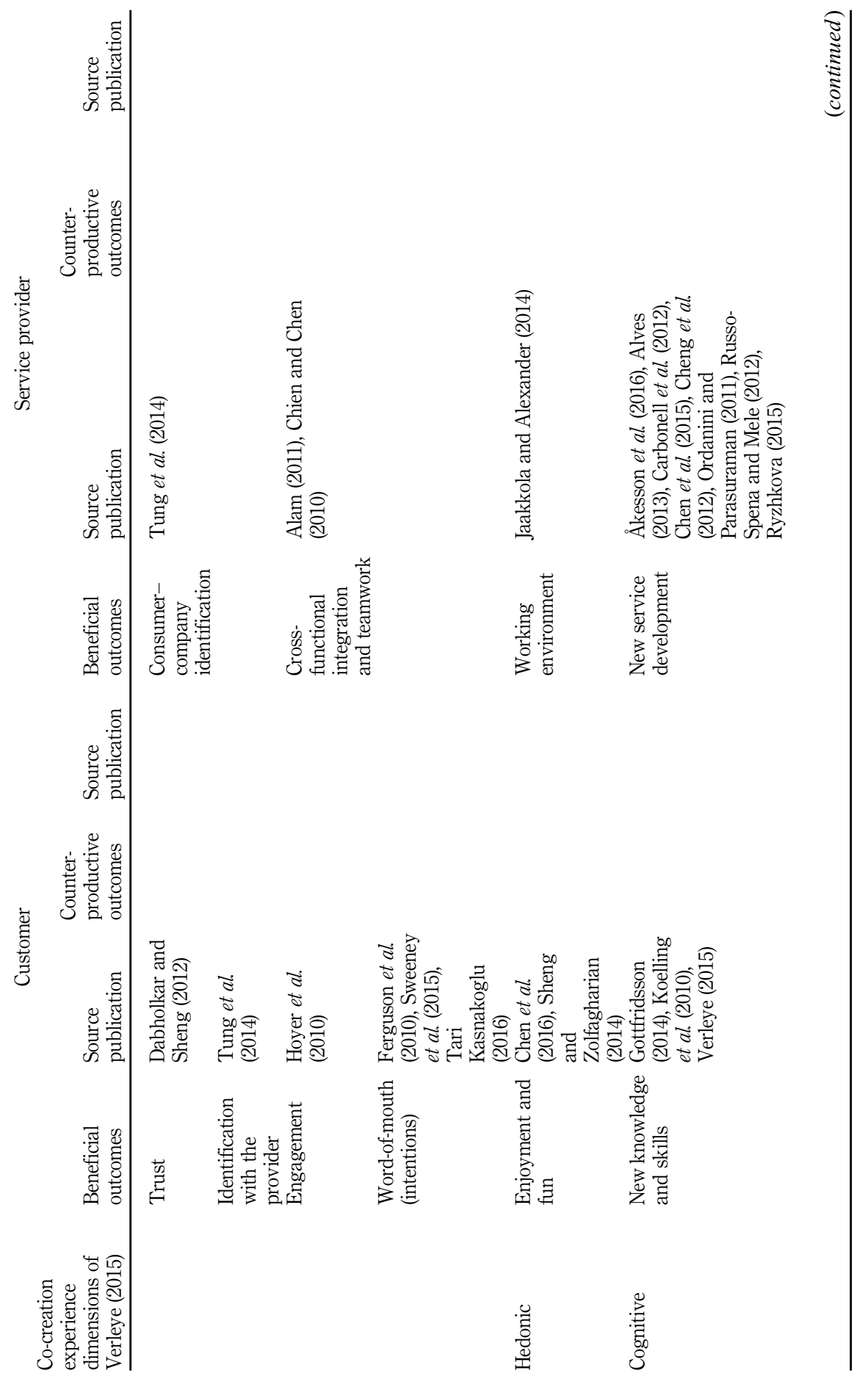




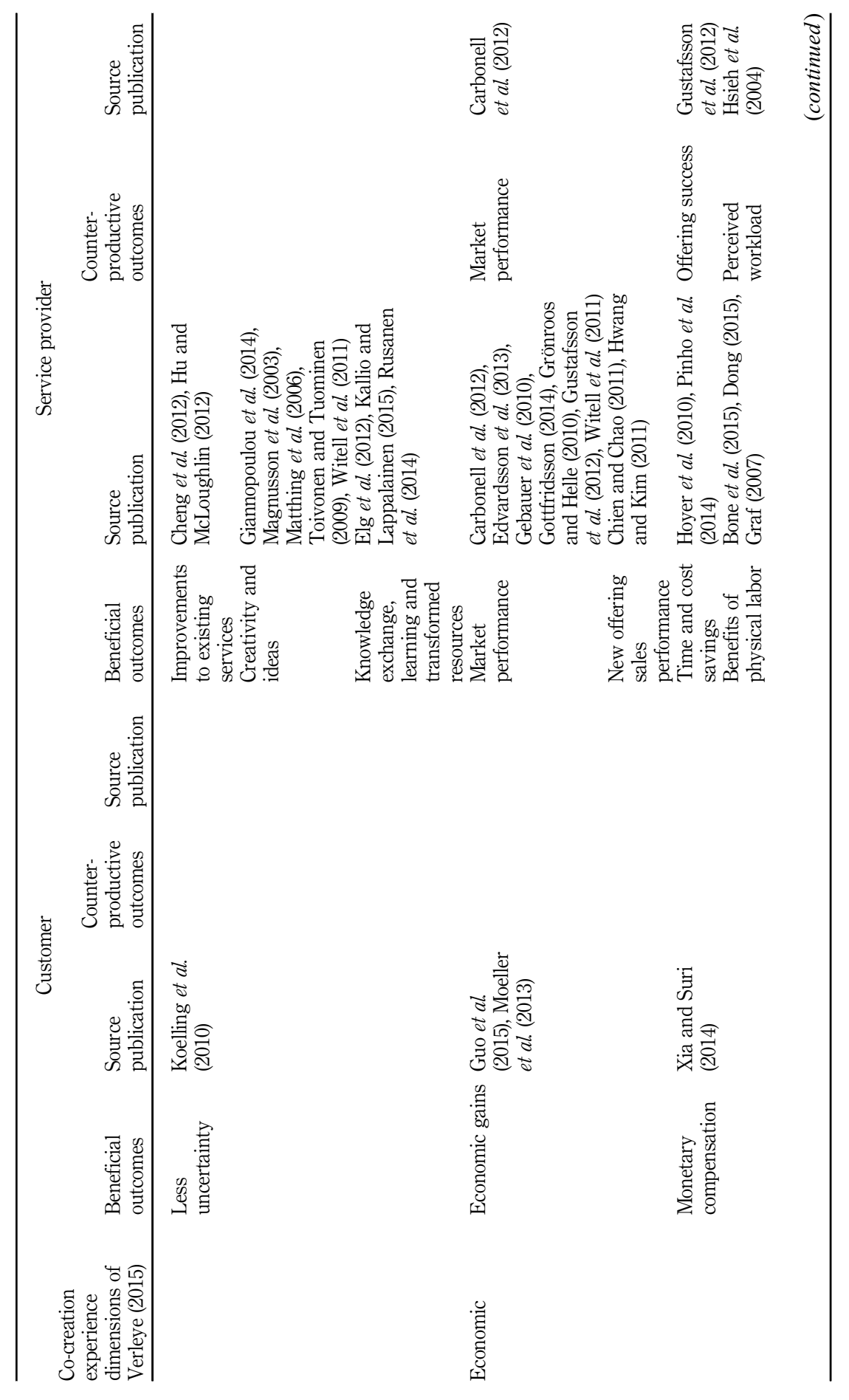

Co-creating

services

663

Table VIII. 
JOSM
29,4

664

Table VIII.

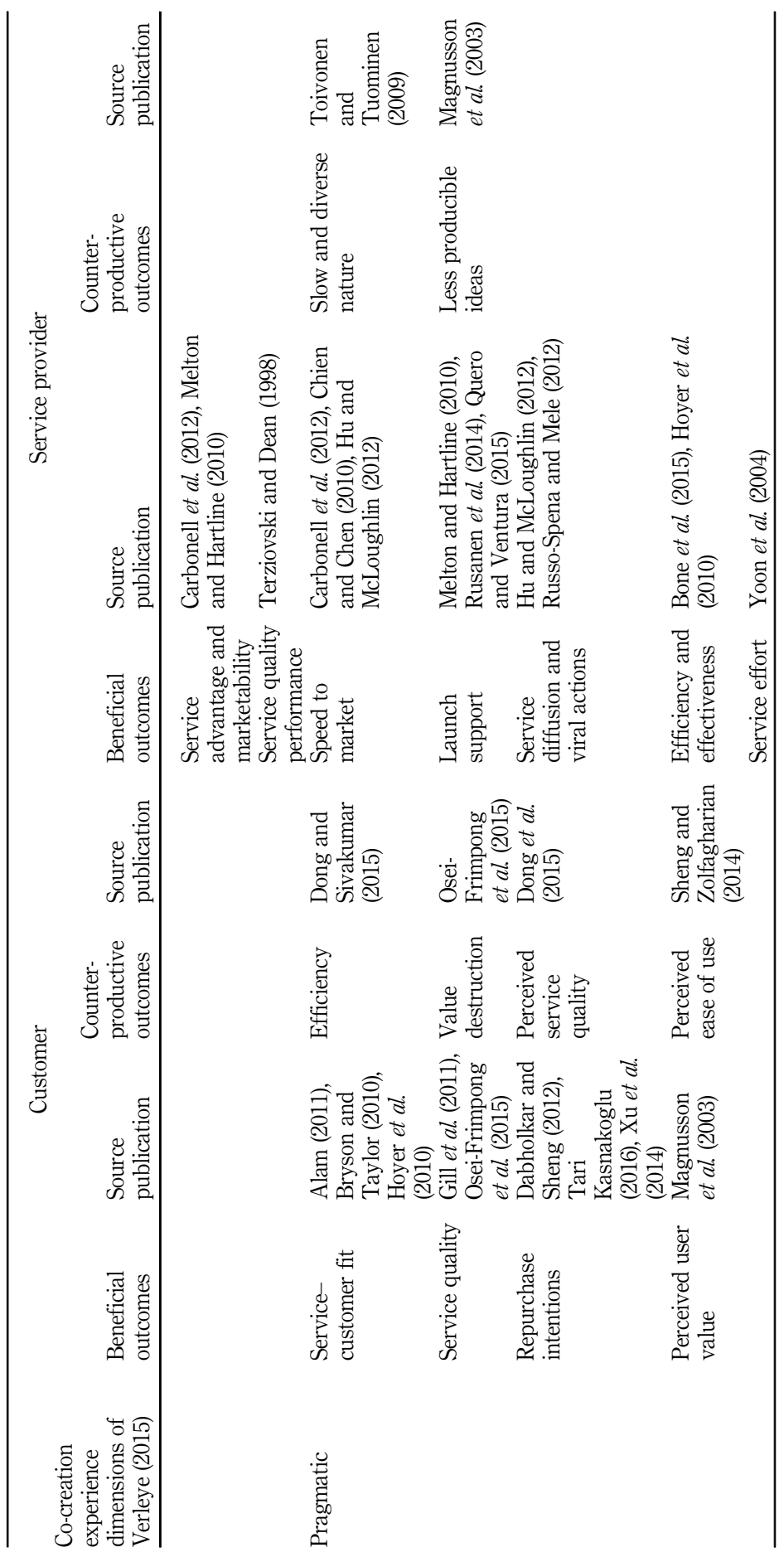


outcomes (Sheng and Zolfagharian, 2014), while the cognitive benefits include new knowledge and skills as beneficial outcomes (Koelling et al., 2010). The economic benefits consist of improved economic gains for the customer (Moeller et al., 2013) and monetary compensation for their efforts (Xia and Suri, 2014). Finally, because co-created services can meet personal needs better, the pragmatic benefits include improved service-customer fit (Alam, 2011), service quality (Gill et al., 2011) and repurchase intentions (Tari Kasnakoglu, 2016).

The beneficial outcomes for customers have received more attention than the counterproductive outcomes. As Table VIII demonstrates, the personal, hedonic, cognitive and economic co-creation experience dimensions for customers contain no counterproductive outcomes. This finding supports Mustak et al. (2013, 2016) who observed a lack of research on counterproductive outcomes following co-creation. An example of a counterproductive social outcome is that following a lack of positive collaboration, customers' trust and commitment may decline; customers' frustrations may increase if they perceive their loyalty to be exploited (Harwood and Garry, 2015). Counterproductive pragmatic outcomes for customers may result from diminished efficiency (Dong and Sivakumar, 2015), possibly due to decreased ease of use (Sheng and Zolfagharian, 2014) or lower perceived service quality (Dong et al., 2015).

Table VIII also displays the outcomes following from the co-creation of services for service providers. The cognitive, economic and pragmatic co-creation experience dimensions point toward several beneficial outcomes. The cognitive benefits for service providers include the knowledge and skills to develop new services and improve existing ones together with their customers (Hu and McLoughlin, 2012; Ryzhkova, 2015). Furthermore, the collaborative act with customers positively influences market performance (Carbonell et al., 2012), profit margins (Witell et al., 2011) and sales performance of the new offering (Chien and Chao, 2011) -all important economic benefits. Pragmatic benefits can be realized through shorter time-to-market when introducing new offerings (Chien and Chen, 2010), peer support for services (Melton and Hartline, 2010) and improved efficiency and effectiveness in operations (Bone et al., 2015). The literature rarely discusses hedonic benefits for service providers, although a case study of customer engagement behavior (Jaakkola and Alexander, 2014) shows how co-creation leads to an improved working environment. Previous research suggests that the co-creation of services can lead to the personal benefits of improved decision support for the service provider (Pinho et al., 2014) and a better provider image (Toivonen and Tuominen, 2009). Social benefits identified include better synergy (Hsieh et al., 2013), contract retention with customers (Burdon et al, 2015) and cross-functional integration and teamwork within the service provider (Alam, 2011; Chien and Chen, 2010).

A major counterproductive personal outcome for the service provider involves knowledge sharing, which leads to increased uncertainty about who owns the service and calls for better service protection against imitation (Hurmelinna-Laukkanen and Ritala, 2010). Possible counterproductive economic outcomes for the service provider that can follow from co-creation include declining market performance (Carbonell et al., 2012) and a negative effect on the product success of radical innovations (Gustafsson et al., 2012). Additionally, employees' job stress, role conflict and perceived workload are interrelated counterproductive outcomes associated with personal, social and economic outcome dimensions for providers (Hsieh et al., 2004; Hsieh and Yen, 2005). More specifically, Hsieh and Yen (2005) proposed that customer participation increases job stress of employees, due to role conflicts between customers and employees following changes in job characteristics.

To clarify the conceptual pluralism surrounding the concept of co-creation in services, the authors further compared and contrasted the identified outcomes against the terminology of co-creating services. Table VII summarizes this comparison and reports on the occurrence of beneficial and counterproductive outcomes across the terminology for customers and service providers.
Co-creating services

665 
JOSM

29,4

666
Cross-comparison of the identified outcomes against the terms used in the same study reveals that literature using the co-creation term suggests a variety of beneficial outcomes for nearly all customer and provider experience dimensions, except for the hedonic dimension. However, the publications addressing co-creation do not identify many counterproductive outcomes; Osei-Frimpong et al. (2015), on the possibility of value destruction, and Gustafsson et al. (2012), on diminished success of the offerings, are the only contributions of co-creation terms to counterproductive outcomes. This finding demonstrates the research gap between the investigation of beneficial and counterproductive outcomes, supporting earlier reviews (Mustak et al., 2013, 2016).

Interestingly, publications using the involvement term are predominantly suggesting outcomes for service providers, with only two publications contributing to customer outcomes - Chen et al. (2016) mentioned a positive effect on customers' moods and Magnusson et al. (2003) proposed improvements in perceived user value. Especially, for the cognitive, economic and pragmatic experience dimensions, there is a broad body of involvement literature proposing outcomes for service providers.

Contrary to involvement literature, publications on the engagement term indicate hardly any outcomes for the service provider, with the exception of Jaakkola and Alexander (2014), who reported on a positive working atmosphere. There are several outcomes mentioned by engagement studies for customers, however, they are focused only on the personal and social experience dimensions. This comprises another difference between the engagement and involvement terms: while there are many outcomes from involvement publications for the cognitive, economic and pragmatic experience dimensions, there are no outcomes from engagement publications on these dimensions. Analogously, there are no outcomes from involvement literature for the personal and social experience dimensions, but many outcomes from engagement literature for these dimensions.

For publications highlighting the participation term, the authors find that the outcomes are relatively evenly divided across the experience dimensions and the customer and service provider perspectives. Notably though, participation literature identifies more counterproductive outcomes than any other term. While counterproductive outcomes for the service provider are mostly suggested for the personal, social and economic dimensions, counterproductive outcomes for the customer are proposed for the pragmatic experience dimension.

Finally, there are only few outcomes suggested by co-production articles and no outcomes specifically mentioned for co-design and co-consumption literature. One possible reason for this finding is that the publications that cover outcomes for co-design, co-production and co-consumption rarely suggest these outcomes for the respective term alone. Any publication that named the same outcome for more than one term was not categorized by this research after a specific term, but under the category "Not specified." When scrutinizing the publications in this category (Chien and Chen, 2010; Gebauer et al., 2010; Hwang and Kim, 2011; Russo-Spena and Mele, 2012; Quero and Ventura, 2015; Witell et al., 2011), many articles appear to include one or more terms of the co-design, co-production and co-consumption terms. Chien and Chen (2010) reported on customer involvement, customer participation and co-production; Gebauer et al. (2010) proposed co-creation, engagement, co-design, co-production and co-consumption (pro-sumption); Russo-Spena and Mele (2012) covered co-creation and co-design; and finally, Quero and Ventura (2015) suggested co-creation, co-design and co-consumption. More specifically, Quero and Ventura (2015) proposed co-design and co-consumption as certain types of co-creation; Chien and Chen (2010) defined co-production as customers' role in the early phases of developing new offerings; Russo-Spena and Mele (2012) termed co-design as a phase of the co-creative innovation process; and Witell et al. (2011) implicated that pro-sumption denotes co-creation, but only during the consumption phase. Conclusively, these findings further support the authors' proposition that co-design, co-production and co-consumption can be considered specific forms of co-creating services that occur in particular phases of the service process. 


\section{Conclusion: an integrative framework for co-creating services}

This focused review set out to conceptually clarify the co-creation of services and name its forms and outcomes. Grounded in the findings of the thematic analysis of forms, themes and outcomes in the examined literature, the authors develop an integrative framework to achieve comprehensive conceptualization of co-creation of services and the associated terminology (Figure 3) and further suggest examples of industry practices for the specific forms of co-creating services (Table IX).

\subsection{The framework}

Figure 3 reflects the properties of the newly developed definition of co-creating services: service providers and customers integrate their resources collaboratively when and if they are involved, engaged and participate in the co-creation of services. This co-creation of services may manifest itself in specific forms depending on the phases of the service process; as co-ideation, co-valuation, co-design, co-testing, co-launching, co-production and co-consumption. For customers and providers, the co-creation of services enables beneficial and counterproductive outcomes, which can be classified into personal, social, hedonic, cognitive, economic and pragmatic experience dimensions. Finally, beyond the customerprovider dyad, the thematic analysis identified the theme of "multi-actor emphasis," which underlines the influence of a contextual, multi-actor network on all activities occurring as part of co-creating services.

In conclusion, involvement, engagement and participation are necessary but not sufficient conditions that must be fulfilled altogether for the co-creation of services to occur (Verleye, 2015; Voorberg et al., 2015; Yi and Gong, 2013); yet these prerequisites cannot ensure that co-creation of services occurs. For beneficial co-creation to take place, both the customer and the service provider must be involved, engaged and participating constructively and actively (Auh et al., 2007; Dong and Sivakumar, 2017). The co-creation of services can manifest itself in specific forms along the phases of the service process. More specifically, the authors use the label "regenerative co-creation" to refer to co-creation forms in earlier phases of the service process that point toward innovating the service - co-ideation, co-valuation, co-design, co-test and co-launch. "Operative co-creation" captures co-production and co-consumption and denotes a customer-specific service event or encounter that may occur again several times, leading at most to incremental innovation.

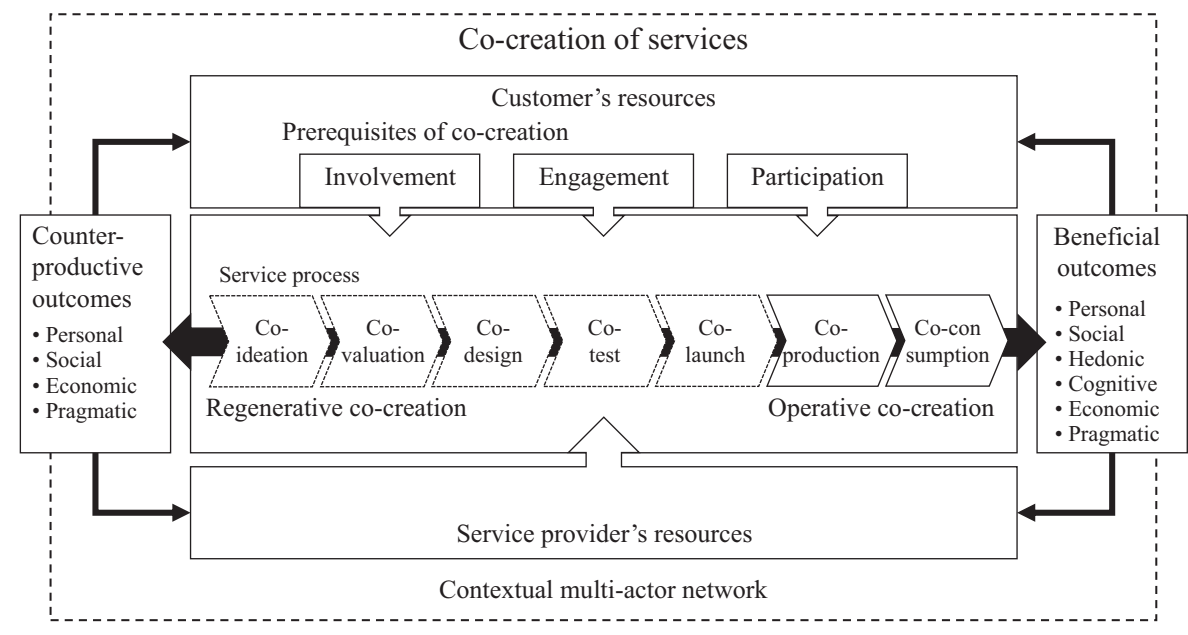

Co-creating services

667
Figure 3. Integrative framework of co-creating services 
JOSM

29,4
Specific forms of

co-creating Industry

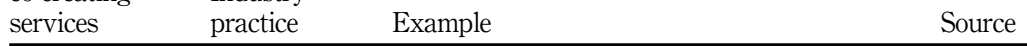

Co-ideation Idea $\quad$ E.ON launched an open idea submission contest Verrinder (2012)

crowdsourcing to find new services through its online

community

668

Lead user LEGO Mindstorm supplies software to members Chesbrough (2011),

involvement to reprogram and develop programmable robots Gyrd-Jones and Kornum (2013)

Co-valuation Commenting Users submit and vote for designs presented by and voting Threadless

Ogawa and Piller (2006),

Russo-Spena and Mele

Co-design Solution Netflix Prize was a competition to find a solution Prpić et al. (2015)

crowdsourcing to improving Netflix's accuracy in predicting the enjoyment level for a user for a given movie based on extant movie preferences

Co-creation DHL fosters co-creation workshops with $\quad$ DHL Solutions \&

workshops customers to co-design solutions that improve Innovations (2017) the service experience

Co-test $\quad$ Open service IBM and customers jointly develop and co-test innovation solutions and share the resulting knowledge as part of the First-of-a-Kind initiative

Co-launch Co-launch At Threadless, besides submitting and voting for designs, users share responsibility for the launch of the design by advertising, shooting for catalogues and wooing new customers

Co-production Co-production IKEA co-produces improvements in family living with its customers by guiding them to assemble their own furniture

Table IX

Examples of industry practices for co-creating services

\section{Co-consumption Brand} communities

\section{The Harley Owners Group (HOG) by}

Harley-Davidson connects highly engaged customers and interacts with them through online and offline channels
Ogawa and Piller (2006), Russo-Spena and Mele (2012)

Normann and Ramirez (1993)

Fournier and Lee (2009)

\subsection{Examples of industry practices}

Table IX provides industry examples of the specific forms of co-creating services. As the examples demonstrate, co-creation can be induced to enhance both the core service as well as supporting and augmenting services (cf. Ozment and Morash, 1994). To collaboratively generate ideas (co-ideation), service providers can host open contests and crowdsourcing events, as E.ON did (Verrinder, 2012). Like LEGO, they could also limit participation to a selected user group (Chesbrough, 2011; Gyrd-Jones and Kornum, 2013). Threadless invited customers to vote, appraise and evaluate ideas for t-shirt designs (co-valuation; Ogawa and Piller, 2006; Russo-Spena and Mele, 2012). Customers can be invited to co-design with the aim of bridging the gap between identified needs and feasible solutions (Russo-Spena and Mele, 2012). For example, Netflix held a competition inviting its audience to help develop recommendations (Prpić et al, 2015) and DHL invited selected stakeholder groups to participate in co-creative design workshops (DHL Solutions \& Innovations, 2017). Other specific forms of co-creating services include co-testing, where customers and providers collaboratively prototype the service before its market introduction, and co-launching by integrating the customer in launch activities (Chesbrough, 2011; Ogawa and Piller, 2006; Russo-Spena and Mele, 2012). As an iconic example of co-production, IKEA redefined the roles and relationships of the traditional furniture business beyond co-producing furniture (Normann and Ramirez, 1993). Finally, how Harley-Davidson interacts with its customers through the brand community HOG illustrates the co-consumption form (Fournier and Lee, 2009). 


\section{Discussion}

Co-creating

\subsection{Research implications}

Reacting to the conceptual pluralism around the concept of co-creating services (Dong and services

Sivakumar, 2017; Galvagno and Dalli, 2014; Voorberg et al., 2015), this paper clarifies, synthesizes and develops knowledge about co-creating services by investigating the existing body of knowledge in five scholarly service journals. First, the terminology for co-creating services emerged from the articles based on the workflow of inductive analysis. Further systematic analyses of the articles investigated the conceptualizations of the terminology; identified themes that illustrate how different aspects of co-creation are emphasized across the service literature set; developed a typology of co-creation outcomes; and synthesized an integrative conceptual framework for co-creating services to support the research streams investigating co-creation and the customer-provider interface in services.

The paper extends the analyses on co-creation and related terminology (Chathoth et al, 2013; Lusch and Vargo, 2006; O'Hern and Rindfleisch, 2010) by providing several new theoretical contributions: first, the study reduces conceptual pluralism around co-creating services by clearly disentangling its relationship to related terminology, such as involvement, engagement, participation, co-design, co-production and co-consumption. Second, the study develops an explicit definition of co-creating services based on conceptual analysis of the identified terminology and the thematic analysis of the literature. Third, the study develops a typology of co-creation outcomes by extending the co-creation experience dimensions of Verleye (2015) by adding the beneficial and counterproductive outcome dimensions, and comparing the outcomes reported for customers and for service providers. Fourth, the study develops an integrative framework of co-creation of services to connect the terminology and to visualize the conceptual dynamics.

The findings of the review encourage using "co-creation of services" as an encompassing concept to integrate the other terms. The thematic analysis shows that the co-creation term as such is the only term that is utilized across all seven themes identified. Furthermore, co-creation has the broadest presence in the experience-centric outcome types identified for both service providers and customers.

Involvement, engagement and participation are identified as necessary prerequisites to co-create, while co-design, co-production and co-consumption are considered specific forms of co-creating services that range from regenerative to operative in nature, depending on the phase of the service process. Comparing the terminology across the associated themes shows that literature using involvement, engagement and participation terms recurrently highlights customer-provider collaboration, which underlines the importance of these terms for the co-creation of services. Literature exploring co-design, co-production and co-consumption usually emphasizes the respective phases of the service process, which further supports the proposition that co-design, co-production and co-consumption can be considered specific forms of co-creating services.

In response to calls for a less abstract and shared understanding of co-creation (Galvagno and Dalli, 2014; Saarijärvi et al., 2013), this paper examines the conceptualizations of co-creating services and shows that no definition appears more than four times across the 80 articles. To introduce conceptual coherence, a thematic analysis revealed emergent concepts associated with different conceptualizations of co-creating services, recognized similar themes that have been expressed using various wordings and synthesized these patterns into an explicit definition of co-creating services (Fereday and Muir-Cochrane, 2006; Green et al., 2017; Thomas and Harden, 2008). The developed definition of co-creating services should increase consistency and support the comparison and synthesis of findings from studies using different terms.

By responding to calls for more research on co-creation outcomes (e.g. Voorberg et al, 2015), this research also differentiates, synthesizes and strengthens the body of knowledge 
JOSM

29,4

670

discussing the outcomes that follow from co-creation. The authors extend existing reviews that cite the shortage of quantitative co-creation studies to consolidate the subsequent outcomes (Voorberg et al., 2015), by grounding the findings in 38 quantitative and 15 mixed methods articles. The typology of outcomes shows that there are beneficial outcomes for service providers and customers across all six co-creation experience dimensions. It further confirms the lack of counterproductive outcomes of co-creation and extends prior reviews that only suggest counterproductive outcomes for service providers, by noting some counterproductive outcomes for customers too (Mustak et al., 2013, 2016). Comparing the terminology across the typology of outcomes suggests that the involvement term is predominantly used to convey outcomes for service providers and focuses on the cognitive, economic and pragmatic experience dimensions. On the contrary, the engagement term mostly relates to outcomes for customers and focuses on the personal and social experience dimensions. Finally, the participation term is associated with outcomes that are relatively evenly divided across the experience dimensions for service providers and customers. Interestingly, this finding shows that the involvement term is used more frequently to denote outcomes for the service provider's side, the engagement term to convey outcomes for the customer's side and the participation term to refer to outcomes for both sides.

Finally, this research nurtures inquiries into the dynamics and content of co-creation (Payne et al., 2008; Pinho et al., 2014) by providing an integrative framework for the co-creation of services. The framework illustrates the newly developed definition of co-creating services, including its forms and outcomes. It further depicts the influence of the contextual multi-actor network, which has been emphasized in the literature using engagement and co-design terms. Overall, the integrated framework of co-creating services contributes to service management research by reducing the confusion around co-creation (Dong and Sivakumar, 2017; Saarijärvi et al., 2013; Voorberg et al., 2015) through the visual representation of its conceptual nature, forms and outcomes.

\subsection{Managerial implications}

Saarijärvi et al. (2013) argued that the emphasis on theorizing around the concept of co-creation leaves practitioners wondering about its practical relevance. Much of this confusion arises from the conceptual pluralism and lack of integrative work. This paper clarifies the dynamics of the terminology and arranges it in the form of an integrative framework, as visualized in Figure 3. Co-creation is connected to topics that are more familiar than "value," in essence the phases of the service process and the experience-centric typology of outcomes. The study also takes a step toward practice by connecting the various forms of co-creation with identified beneficial and counterproductive outcomes.

Service providers must understand these outcomes in order to be able to mitigate counterproductive outcomes of co-creation and to assess the usefulness of their ideas to involve and engage their customers, and then incentivize them accordingly. Furthermore, knowledge of these outcomes may be leveraged to generate internal firm buy-in and motivate employees.

The typology of outcomes (Table VIII) points to several ways to stimulate fruitful collaboration. Participating customers should be actively involved and engaged. Service managers can device different tactics to motivate customers to co-create, highlighting either the recognition customers can get from co-creating (personal dimension), the identification and improved relationship with the provider (social), the enjoyment experienced during collaborative activities (hedonic), the new knowledge and skills gained (cognitive), the monetary compensation offered (economic) or the improved service quality and service-customer fit (pragmatic).

There are also different tactics to motivate employees and garner top-level management support. To incentivize co-creating services in their organization, service managers could emphasize the improved provider image and job satisfaction following co-creation (personal dimension), the potential for contract retention and synergy with customers (social), the 
improved working environment for employees (hedonic), the beneficial effect on new service development and creativity (cognitive), the accelerated market performance and service quality performance (economic) or the improved speed to market and support for novel services (pragmatic).

The suggested typology of outcomes raises awareness of counterproductive outcomes following the co-creation of services. Service organizations may avert counterproductive outcomes by developing strategies to foster trust and commitment to prevent customers feeling that their loyalty is exploited. Appropriate strategies are also needed to counter declining efficiency due to customers' perceptions of diminishing service quality and ease of use. In addition, service managers need to prevent uncertainty about service ownership through service protection. The success of co-creating services may further be improved by developing strategies to reduce role conflict with customers, which causes an increase in employees' work stress.

Finally, the findings of this review support service managers by exemplifying industry practices for the specific forms of co-creating services in Table IX. Service managers seeking to collaborate with customers must first decide in which service phase this co-creation should take place. Different forms of co-creating services may lead to different outcomes, which have to be assessed in order to determine the usefulness of the collaboration idea and effective incentives for participating customers and employees.

\subsection{Limitations}

As with all studies, there are limitations that set boundaries for the generalization of the current findings. First, the study focused on five service research journals to keep the scope of the inductive analysis step manageable. The set of articles thus is a representative and carefully chosen sample, not the entire population of articles on the subject, and hence literature beyond the studied journals could potentially contribute with further analytical content categories. The inductive aspects of the review process would have not been possible with more sources, considering that this study examined the abstracts of 2,466 service journal articles and fully analyzed 80 articles. However, as the current number of articles analyzed is sufficient, the literature analyzed broadly cites studies beyond the journals examined, and most categories saturated strongly in the data set, it is reasonable to consider that the findings are robust.

Second, to keep the conceptual complexity manageable during the analysis, this paper analyzed publications exploring the collaborative act in the customer-provider interface. Of course, while the vast majority of the literature focuses on customer-provider collaboration, other stakeholders exist in collaboration networks.

Finally, the outcomes from co-creation may vary depending on the emotional intensity of the contexts and between commodity vs non-commodity services. The 80 articles spread across 11 different service industries, whereas 27 studies did not specify one particular industry. Finance, healthcare and telecommunications services lead with their 9-13 percent representations, which indicates that industry groups are too small for cross-comparison.

\subsection{Further research}

The study discovers several avenues for further research. While the review concentrated on customer-provider co-creation, the thematic analysis reveals an emerging focus on co-creation in actor networks (e.g. Åkesson et al., 2016; Pinho et al., 2014), indicating that further research beyond the dyadic view is needed. The focused design of the current literature review invites a more exhaustive analysis to cover relevant research across a wider range of disciplines.

Research is needed on the specific forms of co-creating services and subsequent outcomes. Aligning customers' co-creation efforts with requirements, providers need to anticipate which outcomes are most likely to accrue as a result of a specific co-creation form and whether outcomes differ between the forms of co-creation. 
JOSM

29,4

672

The current analysis further identified a gap regarding the counterproductive or "negative" outcomes of co-creating services for the service provider or the customer, which should be more diligently investigated from the perspectives of all parties involved.

Regarding the drivers of co-creating services, what stimulates involvement, engagement and participation needs to be further specified. Service managers can use the typology of outcomes of this paper to develop motivational strategies for customer-provider collaboration, but more research is needed on the relative importance of the outcome dimensions.

Further empirical research should explore the dynamics of co-creating services in practice: how customers become involved, engaged and participate in co-creating services. Also, moderating influences on the relationship between co-creating services and subsequent outcomes need to be explored, as disparities arise even in this rather narrow focus on customer-provider co-creation. For example, Carbonell et al. (2012) found that lead users have a positive effect on service newness, but relationally close customers beyond lead users do not. These outcomes of co-creating services are likely to vary between different contexts, especially due to their different emotional loadings. The dynamics of co-creation need empirical exploration comparing different service settings in order to formulate suitable strategies and approaches for different service contexts.

\section{References}

Akaka, M.A. and Vargo, S.L. (2015), "Extending the context of service: from encounters to ecosystems", Journal of Services Marketing, Vol. 29 Nos 6/7, pp. 453-462.

Åkesson, M., Skålén, P., Edvardsson, B. and Stålhammar, A. (2016), "Value proposition test-driving for service innovation: how frontline employees innovate value propositions", Journal of Service Theory and Practice, Vol. 26 No. 3, pp. 338-362.

Alam, I. (2011), "Process of customer interaction during new service development in an emerging country", The Service Industries Journal, Vol. 31 No. 16, pp. 2741-2756.

Alves, H. (2013), "Co-creation and innovation in public services", The Service Industries Journal, Vol. 33 Nos 7/8, pp. 671-682.

Auh, S., Bell, S.J., McLeod, C.S. and Shih, E. (2007), "Co-production and customer loyalty in financial services”, Journal of Retailing, Vol. 83 No. 3, pp. 359-370.

Bendapudi, N. and Leone, R.P. (2003), "Psychological implications of customer participation in co-production", Journal of Marketing, Vol. 67 No. 1, pp. 14-28.

Bone, S.A., Fombelle, P.W., Ray, K.R. and Lemon, K.N. (2015), "How customer participation in B2B peer-to-peer problem-solving communities influences the need for traditional customer service", Journal of Service Research, Vol. 18 No. 1, pp. 23-38.

Booth, A., Sutton, A. and Papaioannou, D. (2016), Systematic Approaches to a Successful Literature Review, Sage, London.

Braun, V. and Clarke, V. (2006), "Using thematic analysis in psychology", Qualitative Research in Psychology, Vol. 3 No. 2, pp. 77-101.

Bryson, J.R. and Taylor, M. (2010), "Competitiveness by design and inimitability through service: understanding the dynamics of firm-based competition in the West Midlands jewellery and lock industries", The Service Industries Journal, Vol. 30 No. 4, pp. 583-596.

Burdon, S., Mooney, G.R. and Al-Kilidar, H. (2015), "Navigating service sector innovation using co-creation partnerships", Journal of Service Theory and Practice, Vol. 25 No. 3, pp. 285-303.

Carbonell, P., Rodriguez-Escudero, A.I. and Pujari, D. (2012), "Performance effects of involving lead users and close customers in new service development", Journal of Services Marketing, Vol. 26 No. 7, pp. 497-509.

Cermak, D.S., File, K.M. and Prince, R.A. (1994), "Customer participation in service specification and delivery”, Journal of Applied Business Research, Vol. 10 No. 2, pp. 90-97. 
Chang, C.W., Tseng, T.H. and Woodside, A.G. (2013), "Configural algorithms of patient satisfaction, participation in diagnostics, and treatment decisions' influences on hospital loyalty", Journal of Services Marketing, Vol. 27 No. 2, pp. 91-103.

Chang, W. and Taylor, S.A. (2016), "The effectiveness of customer participation in new product development: a meta-analysis", Journal of Marketing, Vol. 80 No. 1, pp. 47-64.

Chathoth, P., Altinay, L., Harrington, R.J., Okumus, F. and Chan, E.S. (2013), "Co-production versus co-creation: a process based continuum in the hotel service context", International Journal of Hospitality Management, Vol. 32, pp. 11-20.

Chen, J.-S., Kerr, D., Tsang, S.-S. and Sung, Y.C. (2015), "Co-production of service innovations through dynamic capability enhancement”, The Service Industries Journal, Vol. 35 Nos 1/2, pp. 96-114.

Chen, Y.-H., Wu, J.-J. and Chien, S.-H. (2016), "Impact of initial trust, involvement, and mood on trusting belief: evidence from the financial industry in Taiwan", Journal of Service Theory and Practice, Vol. 26 No. 1, pp. 91-108.

Cheng, C.C., Chen, J.S. and Tsou, H.T. (2012), "Market-creating service innovation: verification and its associations with new service development and customer involvement", Journal of Services Marketing, Vol. 26 No. 6, pp. 444-457.

Chesbrough, H.W. (2011), "Bringing open innovation to services", MIT Sloan Management Review, Vol. 52 No. 2, pp. 85-90.

Chien, S.H. and Chao, M.-C. (2011), "Intellectual capital and new product sale performance of the financial services industry in Taiwan", The Service Industries Journal, Vol. 31 No. 16, pp. 2641-2659.

Chien, S.-H. and Chen, J.-j. (2010), "Supplier involvement and customer involvement effect on new product development success in the financial service industry", The Service Industries Journal, Vol. 30 No. 2, pp. 185-201.

Dabholkar, P.A. (1990), "How to improve perceived service quality by improving customer participation”, in Dunlap, B.J. (Ed.), Developments in Marketing Science, Academy of Marketing Science, Cullowhee, NC, pp. 483-487.

Dabholkar, P.A. and Sheng, X. (2012), "Consumer participation in using online recommendation agents: effects on satisfaction, trust, and purchase intentions", The Service Industries Journal, Vol. 32 No. 9, pp. 1433-1449.

Deutsche Post DHL Group (2017), "DHL Parcelcopter 3.0”, available at: www.dpdhl.com/en/media relations/specials/parcelcopter.html (accessed August 28, 2017).

De Wulf, K., Odekerken-Schröder, G. and Iacobucci, D. (2001), "Investments in consumer relationships: a cross-country and cross-industry exploration", Journal of Marketing, Vol. 65 No. 4, pp. 33-50.

DHL Solutions \& Innovations (2017), “A closer look”, available at: http://dsi.bach-partner.com/en/ aboutus/index (accessed August 28, 2017).

Dong, B. (2015), "How a customer participates matters: 'I am producing' versus 'I am designing'”, Journal of Services Marketing, Vol. 29 Nos 6/7, pp. 498-510.

Dong, B. and Sivakumar, K. (2015), "A process-output classification for customer participation in services”, Journal of Service Management, Vol. 26 No. 5, pp. 726-750.

Dong, B. and Sivakumar, K. (2017), "Customer participation in services: domain, scope, and boundaries", Journal of the Academy of Marketing Science, Vol. 45 No. 6, pp. 944-965.

Dong, B., Sivakumar, K., Evans, K.R. and Zou, S. (2015), "Effect of customer participation on service outcomes: the moderating role of participation readiness", Journal of Service Research, Vol. 18 No. 2, pp. 160-176.

Edvardsson, B., Tronvoll, B. and Gruber, T. (2011), "Expanding understanding of service exchange and value co-creation: a social construction approach", Journal of the Academy of Marketing Science, Vol. 39 No. 2, pp. 327-339.

Edvardsson, B., Meiren, T., Schäfer, A. and Witell, L. (2013), "Having a strategy for new service development-does it really matter?", Journal of Service Management, Vol. 24 No. 1, pp. 25-44. 
JOSM

29,4

Eisingerich, A.B., Auh, S. and Merlo, O. (2014), "Acta Non Verba? The role of customer participation and word of mouth in the relationship between service firms' customer satisfaction and sales performance", Journal of Service Research, Vol. 17 No. 1, pp. 40-53.

Elg, M., Engström, J., Witell, L. and Poksinska, B. (2012), "Co-creation and learning in health-care service development", Journal of Service Management, Vol. 23 No. 3, pp. 328-343.

Engström, J. and Elg, M. (2015), "A self-determination theory perspective on customer participation in service development”, Journal of Services Marketing, Vol. 29 Nos 6/7, pp. 511-521.

Etgar, M. (2008), "A descriptive model of the consumer co-production process", Journal of the Academy of Marketing Science, Vol. 36 No. 1, pp. 97-108.

Fereday, J. and Muir-Cochrane, E. (2006), "Demonstrating rigor using thematic analysis: a hybrid approach of inductive and deductive coding and theme development", International Journal of Qualitative Methods, Vol. 5 No. 1, pp. 80-92.

Ferguson, R.J., Paulin, M. and Bergeron, J. (2010), “Customer sociability and the total service experience: antecedents of positive word-of-mouth intentions", Journal of Service Management, Vol. 21 No. 1, pp. 25-44.

Fournier, S. and Lee, L. (2009), “Getting brand communities right”, Harvard Business Review, Vol. 87 No. 4, pp. 105-111.

Fuchs, V.R. (1968), The Service Economy, Columbia University Press, New York, NY.

Galvagno, M. and Dalli, D. (2014), "Theory of value co-creation: a systematic literature review", Managing Service Quality: An International Journal, Vol. 24 No. 6, pp. 643-683.

Gatzweiler, A., Blazevic, V. and Piller, F. (2013), "When users take control: managing the dark side of customer co-creation”, The ISPIM Magazine, Vol. 2013 No. 3, pp. 1-2.

Gebauer, H., Johnson, M. and Enquist, B. (2010), "Value co-creation as a determinant of success in public transport services: a study of the Swiss Federal Railway operator (SBB)", Managing Service Quality: An International Journal, Vol. 20 No. 6, pp. 511-530.

Giannopoulou, E., Gryszkiewicz, L. and Barlatier, P.-J. (2014), "Creativity for service innovation: a practice-based perspective”, Managing Service Quality: An International Journal, Vol. 24 No. 1, pp. 23-44.

Gill, L., White, L. and Cameron, I.D. (2011), "Service co-creation in community-based aged healthcare", Managing Service Quality: An International Journal, Vol. 21 No. 2, pp. 152-177.

Gottfridsson, P. (2014), "Different actors' roles in small companies service innovation”, Journal of Services Marketing, Vol. 28 No. 7, pp. 547-557.

Graf, A. (2007), "Changing roles of customers: consequences for HRM”, International Journal of Service Industry Management, Vol. 18 No. 5, pp. 491-509.

Green, M.H., Davies, P. and Ng, I.C. (2017), "Two strands of servitization: a thematic analysis of traditional and customer co-created servitization and future research directions", International Journal of Production Economics, Vol. 192, pp. 40-53.

Greenhalgh, T., Jackson, C., Shaw, S. and Janamian, T. (2016), “Achieving research impact through co-creation in community-based health services: literature review and case study", The Milbank Quarterly, Vol. 94 No. 2, pp. 392-429.

Grönroos, C. (2008), "Service logic revisited: who creates value? And who co-creates?", European Business Review, Vol. 20 No. 4, pp. 298-314.

Grönroos, C. (2011), "Value co-creation in service logic: a critical analysis", Marketing Theory, Vol. 11 No. 3, pp. 279-301.

Grönroos, C. (2012), "Conceptualising value co-creation: a journey to the 1970s and back to the future", Journal of Marketing Management, Vol. 28 Nos 13/14, pp. 1520-1534.

Grönroos, C. and Helle, P. (2010), "Adopting a service logic in manufacturing: conceptual foundation and metrics for mutual value creation", Journal of Service Management, Vol. 21 No. 5, pp. 564-590. 
Grönroos, C. and Ravald, A. (2011), "Service as business logic: implications for value creation and marketing", Journal of Service Management, Vol. 22 No. 1, pp. 5-22.

Grönroos, C. and Voima, P. (2013), "Critical service logic: making sense of value creation and co-creation", Journal of the Academy of Marketing Science, Vol. 41 No. 2, pp. 133-150.

Guo, L., Arnould, E.J., Gruen, T.W. and Tang, C. (2013), "Socializing to co-produce: pathways to consumers' financial well-being”, Journal of Service Research, Vol. 16 No. 4, pp. 549-563.

Guo, L., Lotz, S.L., Tang, C. and Gruen, T.W. (2015), "The role of perceived control in customer value cocreation and service recovery evaluation”, Journal of Service Research, Vol. 19 No. 1, pp. 39-56.

Gustafsson, A., Kristensson, P. and Witell, L. (2012), "Customer co-creation in service innovation: a matter of communication?”, Journal of Service Management, Vol. 23 No. 3, pp. 311-327.

Gyrd-Jones, R.I. and Kornum, N. (2013), "Managing the co-created brand: value and cultural complementarity in online and offline multi-stakeholder ecosystems", Journal of Business Research, Vol. 66 No. 9, pp. 1484-1493.

Harwood, T. and Garry, T. (2015), "An investigation into gamification as a customer engagement experience environment”, Journal of Services Marketing, Vol. 29 Nos 6/7, pp. 533-546.

Hoyer, W.D., Chandy, R., Dorotic, M., Krafft, M. and Singh, S.S. (2010), "Consumer cocreation in new product development”, Journal of Service Research, Vol. 13 No. 3, pp. 283-296.

Hsieh, A.T. and Yen, C.H. (2005), "The effect of customer participation on service providers' job stress", The Service Industries Journal, Vol. 25 No. 7, pp. 891-905.

Hsieh, A.T., Yen, C.H. and Chin, K.C. (2004), "Participative customers as partial employees and service provider workload”, International Journal of Service Industry Management, Vol. 15 No. 2, pp. 187-199.

Hsieh, J.K., Chiu, H.C., Wei, C.P., Yen, H.R. and Cheng, Y.C. (2013), "A practical perspective on the classification of service innovations", Journal of Services Marketing, Vol. 27 No. 5, pp. 371-384.

$\mathrm{Hu}, \mathrm{Y}$. and McLoughlin, D. (2012), "Creating new market for industrial services in nascent fields", Journal of Services Marketing, Vol. 26 No. 5, pp. 322-331.

Hurmelinna-Laukkanen, P. and Ritala, P. (2010), "Protection for profiting from collaborative service innovation", Journal of Service Management, Vol. 21 No. 1, pp. 6-24.

Hwang, J. and Kim, S. (2011), "Factors affecting successful innovation by content-layer firms in Korea", The Service Industries Journal, Vol. 31 No. 7, pp. 1093-1107.

Ind, N. and Coates, N. (2013), "The meanings of co-creation”, European Business Review, Vol. 25 No. 1, pp. 86-95.

Jaakkola, E. and Alexander, M. (2014), "The role of customer engagement behavior in value co-creation: a service system perspective", Journal of Service Research, Vol. 17 No. 3, pp. 247-261.

Jahn, B. and Kunz, W. (2012), "How to transform consumers into fans of your brand", Journal of Service Management, Vol. 23 No. 3, pp. 344-361.

Kallio, K. and Lappalainen, I. (2015), "Organizational learning in an innovation network: enhancing the agency of public service organizations”, Journal of Service Theory and Practice, Vol. 25 No. 2, pp. 140-161.

Kazadi, K., Lievens, A. and Mahr, D. (2016), "Stakeholder co-creation during the innovation process: identifying capabilities for knowledge creation among multiple stakeholders", Journal of Business Research, Vol. 69 No. 2, pp. 525-540.

Kelley, S.W., Donnelly, J.H. Jr and Skinner, S.J. (1990), "Customer participation in service production and delivery", Journal of Retailing, Vol. 66 No. 3, pp. 315-335.

Koelling, M., Neyer, A.-K. and Moeslein, K.M. (2010), "Strategies towards innovative services: findings from the German service landscape", The Service Industries Journal, Vol. 30 No. 4, pp. 609-620.

Landis, J.R. and Koch, G.G. (1977), "The measurement of observer agreement for categorical data", Biometrics, Vol. 33 No. 1, pp. 159-174.

Levitt, T. (1976), "Industrialization of service”, Harvard Business Review, Vol. 54 No. 5, pp. 63-74. 
JOSM

29,4

676

Lovelock, C.H. and Young, R.F. (1979), "Look to consumers to increase productivity”, Harvard Business Review, Vol. 57 No. 3, pp. 168-178.

Lusch, R.F. and Vargo, S.L. (2006), "Service-dominant logic: reactions, reflections and refinements", Marketing Theory, Vol. 6 No. 3, pp. 281-288.

MacInnis, D.J. (2011), “A framework for conceptual contributions in marketing”, Journal of Marketing, Vol. 75 No. 4, pp. 136-154.

Maglio, P.P. and Spohrer, J. (2008), "Fundamentals of service science", Journal of the Academy of Marketing Science, Vol. 36 No. 1, pp. 18-20.

Magnusson, P.R., Matthing, J. and Kristensson, P. (2003), "Managing user involvement in service innovation: experiments with innovating end users", Journal of Service Research, Vol. 6 No. 2, pp. 111-124.

Matthing, J., Sandén, B. and Edvardsson, B. (2004), "New service development: learning from and with customers", International Journal of Service Industry Management, Vol. 15 No. 5, pp. 479-498.

Matthing, J., Kristensson, P., Gustafsson, A. and Parasuraman, A. (2006), "Developing successful technology-based services: the issue of identifying and involving innovative users", Journal of Services Marketing, Vol. 20 No. 5, pp. 288-297.

Mele, C., Colurcio, M. and Russo-Spena, T. (2014), "Research traditions of innovation: goods-dominant logic, the resource-based approach, and service-dominant logic”, Managing Service Quality: An International Journal, Vol. 24 No. 6, pp. 612-642.

Melton, H. and Hartline, M.D. (2015), "Customer and employee co-creation of radical service innovations", Journal of Services Marketing, Vol. 29 No. 2, pp. 112-123.

Melton, H.L. and Hartline, M.D. (2010), "Customer and frontline employee influence on new service development performance", Journal of Service Research, Vol. 13 No. 4, pp. 411-425.

Mende, M. and van Doorn, J. (2015), "Coproduction of transformative services as a pathway to improved consumer well-being: findings from a longitudinal study on financial counseling", Journal of Service Research, Vol. 18 No. 3, pp. 351-368.

Mills, P.K. and Morris, J.H. (1986), "Clients as 'partial' employees of service organizations: role development in client participation”, Academy of Management Review, Vol. 11 No. 4, pp. 726-735.

Moeller, S., Ciuchita, R., Mahr, D., Odekerken-Schröder, G. and Fassnacht, M. (2013), "Uncovering collaborative value creation patterns and establishing corresponding customer roles", Journal of Service Research, Vol. 16 No. 4, pp. 471-487.

Mukherjee, A. and Malhotra, N. (2006), "Does role clarity explain employee-perceived service quality? A study of antecedents and consequences in call centres", International Journal of Service Industry Management, Vol. 17 No. 5, pp. 444-473.

Mulder, M.R., Rapp, J.M., Hamby, A. and Weaver, T. (2015), "Consumer transformation through volunteer service experiences”, The Service Industries Journal, Vol. 35 Nos 15/16, pp. 865-882.

Mustak, M., Jaakkola, E. and Halinen, A. (2013), "Customer participation and value creation: a systematic review and research implications", Managing Service Quality: An International Journal, Vol. 23 No. 4, pp. 341-359.

Mustak, M., Jaakkola, E., Halinen, A. and Kaartemo, V. (2016), “Customer participation management: developing a comprehensive framework and a research agenda", Journal of Service Management, Vol. 27 No. 3, pp. 250-275.

Normann, R. and Ramirez, R. (1993), "From value chain to value constellation: designing interactive strategy”, Harvard Business Review, Vol. 71 No. 4, pp. 65-77.

O’Brien, I.M., Jarvis, W. and Soutar, G.N. (2015), "Integrating social issues and customer engagement to drive loyalty in a service organisation", Journal of Services Marketing, Vol. 29 Nos 6/7, pp. 547-559.

O'Cass, A. and Ngo, L.V. (2011), "Achieving customer satisfaction in services firms via branding capability and customer empowerment”, Journal of Services Marketing, Vol. 25 No. 7, pp. 489-496. 
O'Hern, M.S. and Rindfleisch, A. (2010), "Customer co-creation: a typology and research agenda”, in Malhotra, N.K. (Ed.), Review of Marketing Research, Vol. 6, M.E. Sharpe, New York, NY, pp. 84-106.

Co-creating services

Ogawa, S. and Piller, F.T. (2006), "Reducing the risks of new product development", MIT Sloan Management Review, Vol. 47 No. 2, pp. 65-71.

Oliveira, P. and von Hippel, E. (2011), "Users as service innovators: the case of banking services", Research policy, Vol. 40 No. 6, pp. 806-818.

Ordanini, A. and Parasuraman, A. (2011), "Service innovation viewed through a service-dominant logic lens: a conceptual framework and empirical analysis", Journal of Service Research, Vol. 14 No. 1, pp. 3-23.

Osei-Frimpong, K., Wilson, A. and Owusu-Frimpong, N. (2015), "Service experiences and dyadic value co-creation in healthcare service delivery: a CIT approach", Journal of Service Theory and Practice, Vol. 25 No. 4, pp. 443-462.

Oxford Dictionaries (2018), "Definition of creation in English", available at: https://en.ox forddictionaries.com/definition/creation (accessed March 2, 2018).

Ozment, J. and Morash, E.A. (1994), "The augmented service offering for perceived and actual service quality", Journal of the Academy of Marketing Science, Vol. 22 No. 4, pp. 352-363.

Payne, A.F., Storbacka, K. and Frow, P. (2008), "Managing the co-creation of value", Journal of the Academy of Marketing Science, Vol. 36 No. 1, pp. 83-96.

Pinho, N., Beirão, G., Patrício, L. and Fisk, R.P. (2014), "Understanding value co-creation in complex services with many actors", Journal of Service Management, Vol. 25 No. 4, pp. 470-493.

Pirinen, A. (2016), "The barriers and enablers of co-design for services", International Journal of Design, Vol. 10 No. 3, pp. 27-42.

Prahalad, C.K. (2004), "The co-creation of value-invited commentaries on 'evolving to a new dominant logic for marketing'”, Journal of Marketing, Vol. 68 No. 1, p. 23.

Prahalad, C.K. and Ramaswamy, V. (2000), "Co-opting customer competence", Harvard Business Review, Vol. 78 No. 1, pp. 79-90.

Prahalad, C.K. and Ramaswamy, V. (2004a), "Co-creating unique value with customers”, Strategy \& Leadership, Vol. 32 No. 3, pp. 4-9.

Prahalad, C.K. and Ramaswamy, V. (2004b), "Co-creation experiences: the next practice in value creation”, Journal of Interactive Marketing, Vol. 18 No. 3, pp. 5-14.

Prpić, J., Shukla, P.P., Kietzmann, J.H. and McCarthy, I.P. (2015), "How to work a crowd: developing crowd capital through crowdsourcing", Business Horizons, Vol. 58 No. 1, pp. 77-85.

Quero, M.J. and Ventura, R. (2015), "The role of balanced centricity in the Spanish creative industries adopting a crowd-funding organisational model”, Journal of Service Theory and Practice, Vol. 25 No. 2, pp. 122-139.

Ramirez, R. (1999), "Value co-production: intellectual origins and implications for practice and research", Strategic Management Journal, Vol. 20 No. 1, pp. 49-65.

Ranjan, K.R. and Read, S. (2016), "Value co-creation: concept and measurement", Journal of the Academy of Marketing Science, Vol. 44 No. 3, pp. 290-315.

Romero, D. and Molina, A. (2011), "Collaborative networked organisations and customer communities: value co-creation and co-innovation in the networking era", Production Planning \& Control, Vol. 22 Nos 5/6, pp. 447-472.

Rusanen, H., Halinen, A. and Jaakkola, E. (2014), "Accessing resources for service innovation-the critical role of network relationships", Journal of Service Management, Vol. 25 No. 1, pp. 2-29.

Russo-Spena, T. and Mele, C. (2012), “Five Co-s' in innovating: a practice-based view”, Journal of Service Management, Vol. 23 No. 4, pp. 527-553.

Ryzhkova, N. (2015), "Does online collaboration with customers drive innovation performance?", Journal of Service Theory and Practice, Vol. 25 No. 3, pp. 327-347. 
JOSM

29,4

Saarijärvi, H., Kannan, P. and Kuusela, H. (2013), "Value co-creation: theoretical approaches and practical implications", European Business Review, Vol. 25 No. 1, pp. 6-19.

Sheng, X. and Zolfagharian, M. (2014), "Consumer participation in online product recommendation services: augmenting the technology acceptance model", Journal of Services Marketing, Vol. 28 No. 6, pp. 460-470.

So, K.K.F., King, C., Sparks, B.A. and Wang, Y. (2016), "Enhancing customer relationships with retail service brands: the role of customer engagement", Journal of Service Management, Vol. 27 No. 2, pp. 170-193.

Sweeney, J.C., Danaher, T.S. and McColl-Kennedy, J.R. (2015), “Customer effort in value cocreation activities: improving quality of life and behavioral intentions of health care customers", Journal of Service Research, Vol. 18 No. 3, pp. 318-335.

Tari Kasnakoglu, B. (2016), "Antecedents and consequences of co-creation in credence-based service contexts", The Service Industries Journal, Vol. 36 Nos 1/2, pp. 1-20.

Terziovski, M. and Dean, A. (1998), "Best predictors of quality performance in Australian service organisations", Managing Service Quality: An International Journal, Vol. 8 No. 5, pp. 359-366.

Thomas, J. and Harden, A. (2008), "Methods for the thematic synthesis of qualitative research in systematic reviews", BMC Medical Research Methodology, Vol. 8 No. 45, pp. 1-10.

Thomson Reuters (2015), "Web of Science Social Sciences Citation Index", available at: http://ip-science. thomsonreuters.com/mjl/publist_ssci.pdf (accessed December 1, 2016).

Toivonen, M. and Tuominen, T. (2009), "Emergence of innovations in services", The Service Industries Journal, Vol. 29 No. 7, pp. 887-902.

Tung, W., Liang, A.R.-D. and Chen, S.-C. (2014), "The influence of service orientation and interaction orientation on consumer identification", The Service Industries Journal, Vol. 34 No. 5, pp. 439-454.

Vargo, S.L. and Lusch, R.F. (2004), "Evolving to a new dominant logic for marketing", Journal of Marketing, Vol. 68 No. 1, pp. 1-17.

Vargo, S.L. and Lusch, R.F. (2008), "Service-dominant logic: continuing the evolution", Journal of the Academy of Marketing Science, Vol. 36 No. 1, pp. 1-10.

Vargo, S.L. and Lusch, R.F. (2016), "Institutions and axioms: an extension and update of service-dominant logic", Journal of the Academy of Marketing Science, Vol. 44 No. 1, pp. 5-23.

Vargo, S.L., Maglio, P.P. and Akaka, M.A. (2008), "On value and value co-creation: a service systems and service logic perspective”, European Management Journal, Vol. 26 No. 3, pp. 145-152.

Verhoef, P.C., Beckers, S.F. and van Doorn, J. (2013), "Understand the perils of co-creation”, Harvard Business Review, Vol. 91 No. 9, p. 28.

Verleye, K. (2015), "The co-creation experience from the customer perspective: its measurement and determinants", Journal of Service Management, Vol. 26 No. 2, pp. 321-342.

Verrinder, J. (2012), "E.ON and 100\% Open Launch Crowdsourcing Project", available at: www. research-live.com/article/news/eon-and-100open-launch-crowdsourcing-project/id/4006939 (accessed November 3, 2016).

Voorberg, W.H., Bekkers, V.J. and Tummers, L.G. (2015), "A systematic review of co-creation and co-production: embarking on the social innovation journey", Public Management Review, Vol. 17 No. 9, pp. 1333-1357.

Witell, L., Kristensson, P., Gustafsson, A. and Löfgren, M. (2011), "Idea generation: customer co-creation versus traditional market research techniques", Journal of Service Management, Vol. 22 No. 2, pp. 140-159.

Xia, L. and Suri, R. (2014), “Trading effort for money: consumers' cocreation motivation and the pricing of service options", Journal of Service Research, Vol. 17 No. 2, pp. 229-242.

Xu, Y., Marshall, R., Edvardsson, B. and Tronvoll, B. (2014), "Show you care: initiating co-creation in service recovery”, Journal of Service Management, Vol. 25 No. 3, pp. 369-387. 
Yen, H.J.R., Gwinner, K.P. and Su, W. (2004), "The impact of customer participation and service expectation on Locus attributions following service failure", International Journal of Service Industry Management, Vol. 15 No. 1, pp. 7-26.

Co-creating services

Yi, Y. and Gong, T. (2013), "Customer value co-creation behavior: scale development and validation", Journal of Business Research, Vol. 66 No. 9, pp. 1279-1284.

Yoon, M.H., Seo, J.H. and Yoon, T.S. (2004), "Effects of contact employee supports on critical employee responses and customer service evaluation", Journal of Services Marketing, Vol. 18 No. 5, pp. 395-412.

Zaichkowsky, J.L. (1985), "Measuring the involvement construct", Journal of Consumer Research, Vol. 12 No. 3, pp. 341-352.

Zwass, V. (2010), "Co-creation: toward a taxonomy and an integrated research perspective", International Journal of Electronic Commerce, Vol. 15 No. 1, pp. 11-48.

Zwick, D., Bonsu, S.K. and Darmody, A. (2008), "Putting consumers to work: co-creation and new marketing govern-mentality", Journal of Consumer Culture, Vol. 8 No. 2, pp. 163-196.

\begin{abstract}
About the authors
Anna-Sophie Oertzen is an Early Stage Researcher at the Service Design for Innovation Network (SDIN) funded by the European Union's Horizon 2020 Research and Innovation Programme. As PhD Candidate, she is currently employed by KISD, the Köln International School of Design, and enrolled at the Department of Marketing and Supply Chain Management of the School of Business and Economics at Maastricht University. Her main research interests evolve around service marketing, service design and service innovation. Anna-Sophie Oertzen is the corresponding author and can be contacted at: anna-sophie.oertzen@th-koeln.de

Gaby Odekerken-Schröder is Professor in Customer-Centric Service Science at Maastricht University. She is Head of the Department of Marketing and Supply Chain Management at Maastricht University. Her main research fields are services and relationship marketing. Her research has been published in Journal of Marketing, Journal of Retailing, Journal of Service Research, Journal of Business Research, International Marketing Review, European Journal of Marketing, Journal of Retailing and Consumer Services, Journal of Consumer Marketing and many other international journals. Her teaching time is dedicated to developing high-quality courses for Bachelor, Master, $\mathrm{PhD}$ and executive students.

Saara A. Brax is Postdoctoral Researcher at the REFLEX Research Platform at Lappeenranta University of Technology (LUT), School of Business and Management (LBM), where her research focuses on sustainable service business, sustainable energy production, servitization and digitalization. Before joining LUT in 2017, Saara Brax worked as Postdoctoral Researcher, funded by the Academy of Finland, at the Department of Industrial Engineering and Management, Aalto University, focusing on various topics in services and operations management, in the B2B and industrial services context. Her work has been published in Journal of Service Management (JoSM), International Journal of Operations and Production Management (IJOPM), Industrial Marketing Management and other journals. She has co-guest edited special issues for JoSM and IJOPM.

Birgit Mager is Professor of Service Design and Head of the Master Program at KISD, the Köln International School of Design, Institute of the Technical University Cologne, Germany. Over the past 22 years, she has been a leading figure in developing the theory and practice of service design. Her publications and lectures have contributed to the establishment of service design as an independent research discipline. Birgit Mager is Co-founder and President of the International Service Design Network (SDN) and Publisher of Touchpoint, the journal for Service Design.
\end{abstract}

For instructions on how to order reprints of this article, please visit our website:

www.emeraldgrouppublishing.com/licensing/reprints.htm

Or contact us for further details: permissions@emeraldinsight.com 